\title{
Nanomaterials in Targeting Cancer Stem Cells for Cancer Therapy
}

\author{
Weiwei Qin, Guan Huang, Zuanguang Chen * and Yuanqing Zhang * \\ Institute of Medical Instrument and Application, School of Pharmaceutical Sciences, Sun Yat-Sen University, Guangzhou, \\ China
}

Cancer stem cells (CSCs) have been identified in almost all cancers and give rise to metastases and can also act as a reservoir of cancer cells that may cause a relapse after surgery, radiation, or chemotherapy. Thus they are obvious targets in therapeutic approaches and also a great challenge in cancer treatment. The threat presented by CSCs lies in their unlimited proliferative ability and multidrug resistance. These findings have necessitated an effective novel strategy to target CSCs for cancer treatment. Nanomaterials are on the route to providing novel methods in cancer therapies. Although, there have been a large number of excellent work in the field of targeted cancer therapy, it remains an open question how nanomaterials can meet future demands for targeting

OPEN ACCESS

Edited by:

Hervé Emonard,

University of Reims Champagne-Ardenne, France

Reviewed by:

João Conde,

Massachusetts Institute of

Technology, USA

Mirco Raffini,

IRST Srl IRCCS, Italy

*Correspondence:

Zuanguang Chen

chenzg@mail.sysu.edu.cn

Yuanqing Zhang

zhangyq65@mail.sysu.edu.cn

Specialty section:

This article was submitted to

Pharmacology of Anti-Cancer Drugs,

a section of the journal

Frontiers in Pharmacology

Received: 30 October 2016 Accepted: 03 January 2017

Published: 18 January 2017

Citation:

Qin W, Huang G, Chen Z and Zhang Y (2017) Nanomaterials in Targeting Cancer Stem Cells for Cancer Therapy. Front. Pharmacol. 8:1. doi: 10.3389/fphar.2017.00001 and eradicating of CSCs. In this review, we summarized recent and highlighted future prospects for targeting CSCs for cancer therapies by using a variety of nanomaterials.

Keywords: cancer stem cells, multidrug resistance, unlimited proliferation, nanomaterials, targeted therapies

\section{INTRODUCTION}

With the financial support of government and society for cancer research, progress has been made in the development of innovative strategies for cancer therapy. However, Cancer still remains one of the deadliest diseases affecting our health, cancer relapse and metastasis are common in patients accepting traditional chemotherapy or radiotherapy. The failure of traditional therapies may be ascribed to a relatively rare subpopulation of cancer cells exist in tumor, called cancer stem cells (CSCs). Since Bonnet and Dick (1997) isolated a small portion of leukemia-initiating cells with features similar to stem cells, researches seemed to focus on isolating CSCs by specific identifying markers. Further researches of other tumor types have identified CSCs in almost all cancers, including prostate (Collins et al., 2005; Maitland and Collins, 2008; Lang et al., 2009), lung (Eramo et al., 2007), colon (O’Brien et al., 2007; Ricci-Vitiani et al., 2007), pancreatic (Hermann et al., 2007; Li et al., 2007), gastric (Fukuda et al., 2009), breast (Al-Hajj et al., 2003), glioma (Galli et al., 2004; Bao et al., 2006), and brain (Hemmati et al., 2003; Singh et al., 2003) cancers. These CSCs exhibit several characteristics, including self-renewal, differentiation into multiple cell types, expression of ATP-binding cassette (ABC) pumps that enable them to resist chemotherapeutic agents, and ionizing radiations.

A variety of nanomaterial, such as DNA (e.g., origami and tetrahedron), carbon (e.g., graphene and nanodiamond), noble metal (e.g., gold and silver nanoparticles), organic polymers, and liposome nanoparticles, with various sizes and modifications to their surfaces can be easily prepared and offer promising means for developing solutions in CSC therapy (Tomuleasa et al., 2012; Orza et al., 2013). Nanomaterial is on the route to providing novel breakthroughs in targeted therapy. During the past decade, nanotechnology and nanomaterial have been widely integrated in biomedical research, providing new strategies for cell imaging 
(Huang et al., 2006; Kong et al., 2012; Li et al., 2014), siRNA and drug delivery (Panyam and Labhasetwar, 2003; Lee et al., 2010; Malmsten, 2013), and targeted cancer therapy (BrannonPeppas and Blanchette, 2004; Loo et al., 2005; Bild et al., 2006). All these mentioned should be attributed to the unique properties of these nanomaterial, such as high surface to volume ratio, easiness to be modified, unique optical properties, quantum-size effects (Whitesides et al., 1991). Taking advantage of and combine the excellent properties of various nanomaterials will further provide better solutions for targeted and controlled elimination of CSCs in the future. The purpose of this review is to summarize recent progress in the applications of various nanomaterials for targeting CSCs.

\section{THE BIOLOGY OF CANCER STEM CELLS}

Cells that have the ability to self-renewal and generate mature cells of a specific tissue through differentiation are defined as stem cells. However, tumors may often result from the conversion of normal stem cells, and similar self-renewal can be regulated between stem cells and cancer cells including CSCs-a rare, phenotypically distinct subset of cells that have the capacity to form new tumors (Hamburger and Salmon, 1977; Figure 1). Recent studies indicated that normal stem cells in hematopoietic system are the targets of transforming mutations, and cancer cell proliferation is driven by CSCs. CSC and normal stem cell share a lot of properties. And the most important one is that both of them have unlimited potential (Reya et al., 2001) for self-renewal that promote tumorigenesis and give rise to new (normal or abnormal) tissues. Moreover, CSCs (self-renewal either inherent or acquired) can produce cells that lack longterm self-renewal ability but preserve dividing capability. Thus, CSCs can be thought of as tumorigenic cells that go through an anomalous and scanty regulated process of tumorigenesis, which is similar to what normal stem cells do.

\section{THE NECESSITY OF TARGETING CANCER STEM CELLS}

Cancer cells can acquire resistance to conventional approaches for cancer treatment such as chemotherapy and radiotherapy (Dean et al., 2005; Eyler and Rich, 2008) by a variety of mechanisms (Dean et al., 2005), including the mutation or overexpression of the drug target, inactivation of the drug, or elimination of the drug from the cell. Drug resistance and cancer metastasis are the two primary problems for the therapy of cancer. Recent studies indicated that endothelial cells can protect normal stem cells and cancer cells from radiation damage (Garcia-Barros et al., 2003; Bao et al., 2006; Diehn and Clarke, 2006). On the basis of CSCs concept, an alternative model posits that the CSCs are naturally resistant to chemotherapy through their quiescence, $\mathrm{ABC}$-transporter expression, and their capacity for DNA repair as they self-renewal, which allow them to expand the population of tumor cells following with chemotherapy or radiotherapy. Furthermore, the survival of residual CSCs is thought to be one of the factors that drives the onset of tumor recurrence, distant metastasis, and drug-resistance, which is a significant clinical problem for the effective treatment of cancer. Conventional chemotherapeutic agents are not only uneasily to accept but also unable to destroy the drug-resistant CSCs, thus it demands a novel approach for cancer therapy. If the chemotherapeutic agents used can efficiently target against CSCs (Stupp and Hegi, 2007), then it might be more effective in killing them. Since more and more efficiently new diagnostic markers (such as, CD44+, CD90+, CD133+, and so on) and therapeutic targets expressed by the stem cells have been found, solid CSCs can be identified prospectively and isolated efficiently. Thus, CSC-based therapies may don't remit cancers at the beginning, but they may eventually cure cancers successfully.

\section{APPLICATIONS OF NANOMATERIALS FOR CSC TARGETING}

Nanomaterials have attracted much attention during the past few decades and will attract more attention in the future owing to their unique optical, chemical, and electronic properties (Manchikanti and Bandopadhyay, 2010; Chen et al., 2013). On the basis of these unique properties, they have been applied in a wide spectrum of fields, including catalysis (Thompson, 2007; Luo et al., 2010; Diao and Cao, 2011; Zheng et al., 2011; Li et al., 2015), plasmonic imaging ( $\mathrm{Li}$ et al., 2013; Peng et al., 2015), biochemical sensors (Orza et al., 2010; Zheng et al., 2011; Qin et al., 2015; Xu Y. et al., 2015), tumor cell detection (Lu et al., 2010), targeted therapy (Kumar et al., 2012), and so on. The unique characteristics of nanomaterials mainly benefit from their high surface to volume ratio compared with their respective bulk counterparts. The large quantities of surface atoms of nanomaterials enable them to have outstanding surface properties that can be utilized for the modification of anti-cancer drugs, various active agents, and targeting molecules commonly used in cancer therapy. Scheme 1 summarizes the mechanisms of the engineered nanoparticles for drug delivery in cancer stem cell therapy. In combination with the latest findings in the area of CSC researches, nanomaterials will bring new opportunities in detecting and targeting of CSCs.

\section{CARBON NANOMATERIALS IN CSC TARGETING}

During the last decade, carbon nanotechnology has achieved rapid development, allotropes of carbon, especially graphene, diamond and carbon nanotubes, have found a wide range of applications in industry and biomedicine. Carbon nanomaterials have also attracted extensive attention from clinical scientists in frontier research and they were used as potential agents in anticancer therapies.

\section{GRAPHENE OXIDE}

Graphene began to attract widespread attention since single layers of graphite were obtained by Novoselov et al. (2004) and it was regarded as the most promising material for transistor 


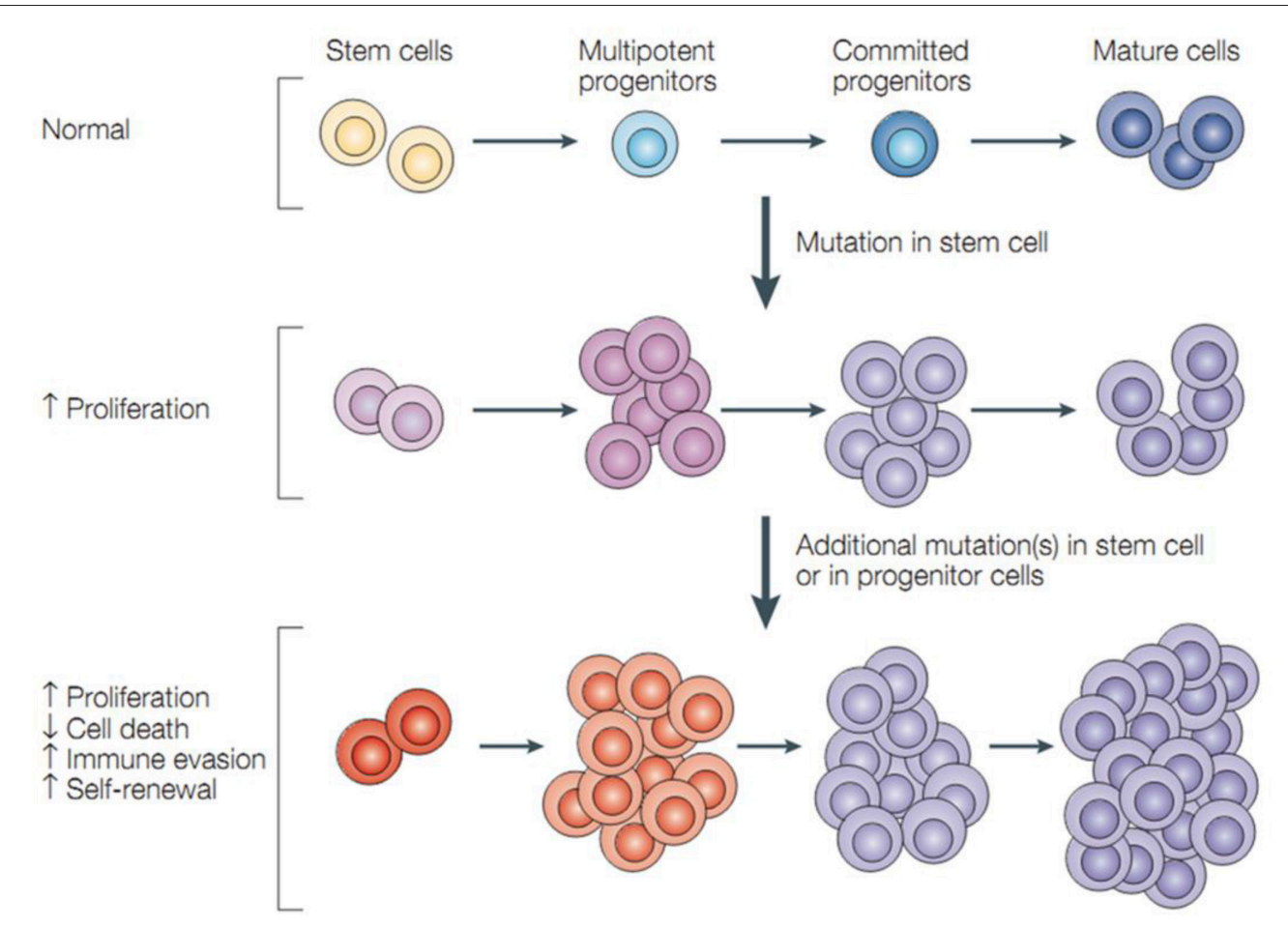

FIGURE 1 | Cancer stem cells and tumor progression. Normal stem cells give rise to multipotent progenitor cells, committed progenitors and mature, differentiated cells. Mutations in a stem cell give rise to a stem cell with aberrant proliferation and result in a pre-malignant lesion. Additional mutations lead to the acquisition of further increased proliferation, decreased apoptosis, evasion of the immune system, and further expansion of the stem-cell compartment that is typical of malignant tumors (Dean et al., 2005).

production that could replace traditional semiconducting materials. Graphene oxide (GO) is a graphene derivative with carbon atoms linked to oxygen functional groups which confers an extraordinary chemical versatility. Thus, the surface of graphene can be easily modified with various biochemical molecules and agents of interest, which enable graphene an excellent carrier of drugs or nucleic acids for targeted cancer therapies.

Previous studies have shown that GO can be used for targeted cancer therapies, prevent tumor growth and inhibit tumor cell migration (Tian et al., 2011; Gonçalves et al., 2013; Gurunathan et al., 2015). In 2014, Jung et al. reported a photothermal therapy based on transdermal nano-graphene oxide-Hyaluronic acid (NGO-HA) conjugates for melanoma skin cancer by using near-infrared (NIR) laser. Because the melanoma tissues of mice are relatively leaky and express high levels of HA receptors, thus NGO-HA could easily penetrate and retain in the tumor tissues for ablating tumor efficiently without recurrence (Jung et al., 2014). However, studies that exploited GO in CSC therapy for cancer treatment is rare. Fiorillo et al. demonstrated that GO is efficient in inhibiting tumor-sphere formation in six independent cancer cell lines, across multiple tumor types (prostate, ovarian, breast, lung, pancreatic, and brain cancer). They employed the tumor sphere assay, which functionally measures the tumor sphere formation and expansion from single CSCs under anchorage-independent conditions, to evaluate the GO-targeted therapy. The obtained results suggested that GO specifically targets a global phenotypic property of CSCs and it may reduce the number of bonafide CSCs by inducing their differentiation and inhibiting their proliferation (Figure 2A, Fiorillo et al., 2015). In a word, the author here present evidence that GO based therapy may be effective in exterminating CSCs by inhibiting several key signal pathways and then inducing CSC differentiation.

\section{CARBON NANOTUBES}

Carbon nanotubes are cylindrical graphene nanostructures with unique properties, such as water-solubility, cell membrane penetrability, high drug-loading ability, selective retention in the tumor, low toxicity, photothermal, photoacoustic, and Raman properties which are valuable for nanotechnology and clinical research (Shao et al., 2013; Wu et al., 2014). In 2012, Burke et al. demonstrated that breast cancer stem cells (BCSCs) are sensitive to carbon nanotube-mediated thermal treatment and lose their long-term proliferative capacity after nanotube-mediated thermal therapy (Burke et al., 2012). Therefore, the nanotubemediated thermal treatment can simultaneously eliminate both the differentiated cells that constitute the bulk of a tumor and the BCSCs that drive tumor growth and recurrence. In 2014, a gastric CSCs-specifically targeting drug delivery system (SAL-SWNTCHI-HA complexes) based on chitosan(CHI) coated single wall carbon nanotubes (SWNTs) loaded with salinomycin (SAL) functionalized with hyaluronic acid (HA) were fabricated by 


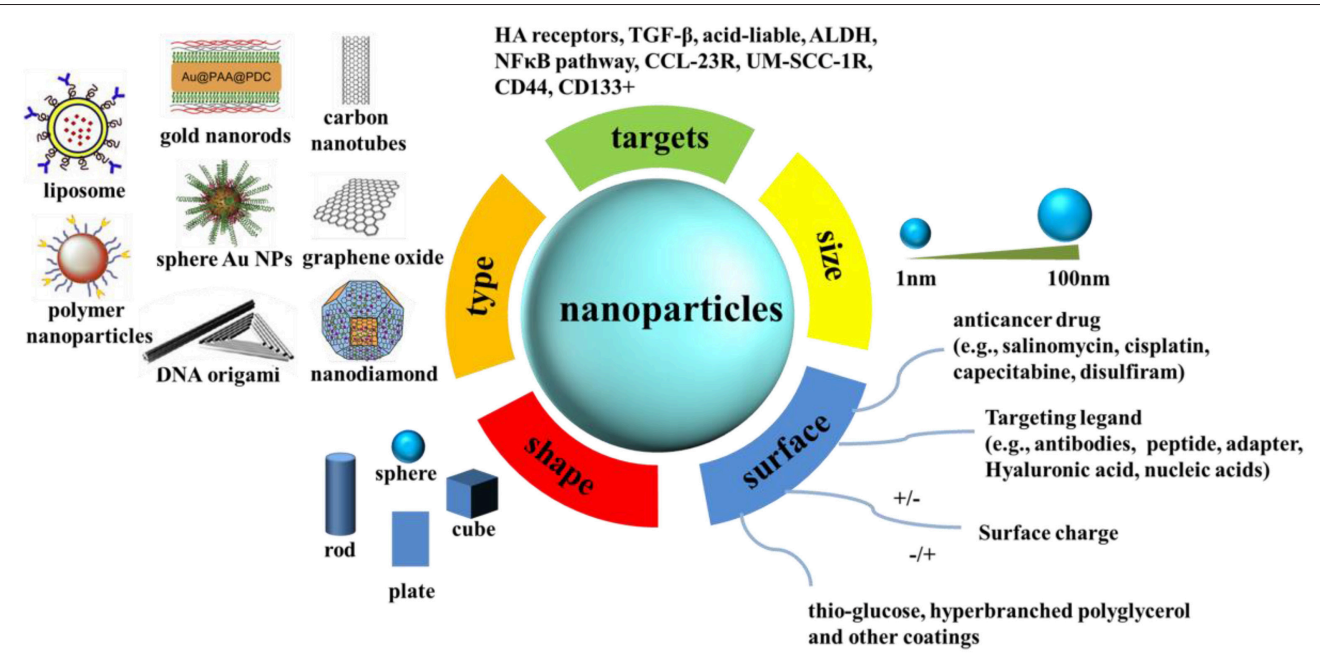

SCHEME 1 | The mechanisms of the engineered nanoparticles for drug delivery in cancer stem cell therapy. A summary of nanoparticles that have been explored as carriers for drug delivery in cancer stem cell therapy, together with illustrations of biophysicochemical properties.

A

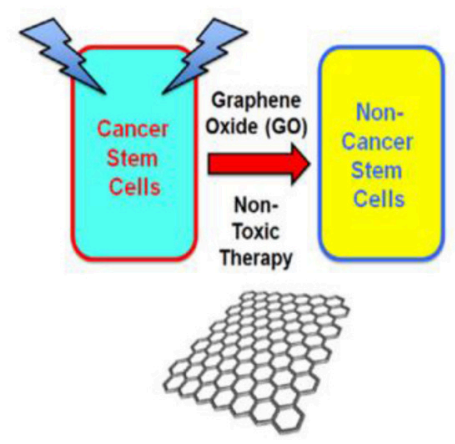

B

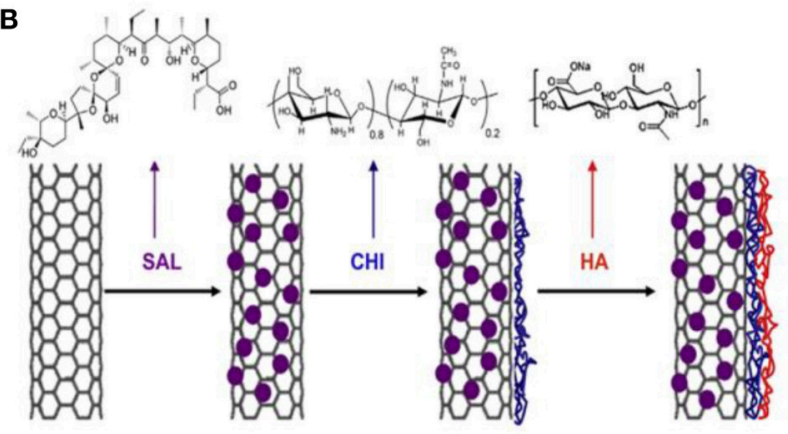

SAL-SWNTS SAL-SWNTS-CHI SAL-SWNTS-CHI-HA

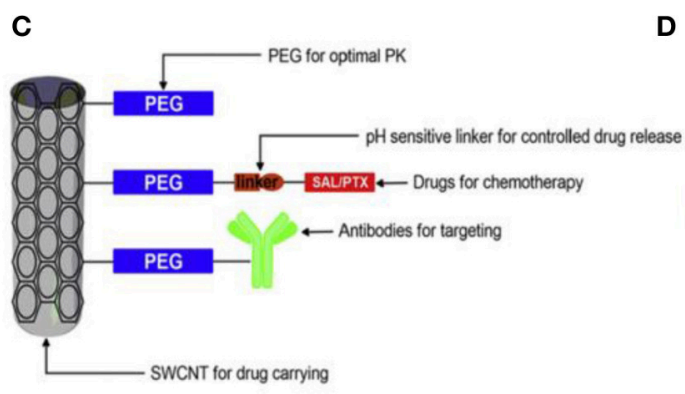

D

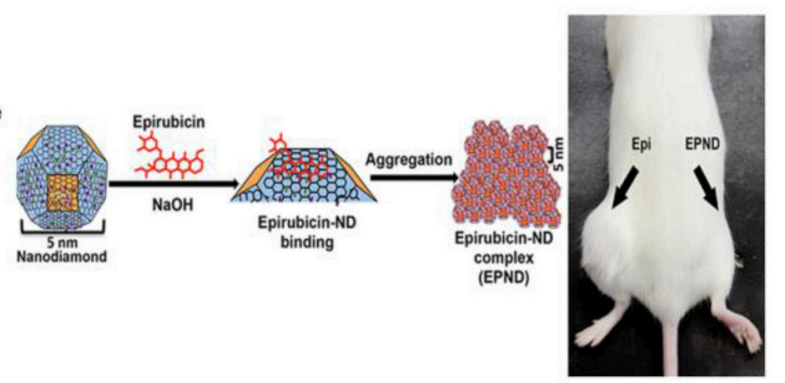

FIGURE 2 | (A) Graphene oxide (GO): Targeting cancer stem cells with differentiation-based nano-therapy. The current mechanistic studies suggest that GO could directly be used as a therapeutic for targeting cancer stem cells (CSCs), because of its ability to induce differentiation. In this context, we might envision that GO could be used to clear residual CSCs, with the aim of preventing tumor recurrence and distant metastasis, thereby providing a practical means for achieving "differentiation-based nano-therapy" (Fiorillo et al., 2015); (B) Schematic illustration of the preparation process of SAL-SWNTs-CHI-HA [chitosan(CHI) coated single wall carbon nanotubes (SWNTs) loaded with salinomycin (SAL) functionalized with hyaluronic acid (HA); Yao et al., 2014]; (C) Schematic diagram illustrating the concept of functionalized SWCNTs as drug carriers (Al Faraj et al., 2016b); (D) Left: schematic model showing surface and chemical structure of (ND) and Epirubicin (Epi), synthesis and aggregation of Epirubicin-nanodiamond complex (EPND). ND represented in truncated octahedron structure with different surface charge denoted with color. ND surface functional group indicated, including benzene ring, carboxyl group, and hydrogen group. Molecular skeleton representing carbon, oxygen and nitrogen atoms in Epi molecule was shown in red. Synthesis of EPND was performed under basic condition of $2.5 \mathrm{mM} \mathrm{NaOH}$ through physical adsorption between Epi and ND. Aggregation around $90 \mathrm{~nm}$ was formed after EPND synthesis. Right: representative image shows that EPND can inhibit tumor-initiation in murine hepatic tumor allografts (Wang et al., 2014). 
Yao et al. The constructed system was shown to have ability to selectively eliminate gastric CSCs (Figure 2B, Yao et al., 2014). Al Faraj et al. developed a strategy that employed biocompatible multimodal SWCNTs functionalized with CD44 antibodies and confirmed the enhanced selective targeting of anti-CD44, which provided encouraging results for efficient targeting of breast CSCs and perspectives for further clinical studies (Al Faraj et al., 2016a). Soon afterwards, the same group combined Paclitaxel and Salinomycin drugs conjugated SWCNTs (Figure 2C) to actively target both breast cancer and CSCs in xenograft murine model and the results confirmed the enhanced therapeutic effect of the combined therapy compared to treatment with individual drug-conjugated nanocarriers or free drug suspensions. Thus, the developed conjugated SWCNTs drug delivery system holds great promise for effective breast cancer therapy by targeting both cancer cells and CSCs (Al Faraj et al., 2016b).

\section{NANODIAMOND}

Nanodiamonds are truncated semi-octahedral carbon structures, and the surface of which can be functionalized with a wide variety of biological and chemical agents, including small molecules, therapeutic and targeting biomolecules, genetic material as well as imaging agents (Liu et al., 2009). Among a wide variety of nanomaterials-based vehicles, nanodiamonds (NDs) have shown outstanding delivery ability and excellent biocompatibility (Zhang et al., 2016). Zhao et al. have demonstrated that detonation nanodiamond with hyperbranched polyglycerol coating (dND-PG) loaded with anticancer drug and led by efficient targeting moiety can realize highly preferential toxicity to the intended tumor cells through specific uptake mechanisms, while with minimum uptake and toxicity in macrophages (Zhao et al., 2014). Nanodiamond-drug complex by physical adsorption of Epirubicin on nanodiamonds was also fabricated and was demonstrated to be a highly effective nanomedicinebased approach to overcome chemoresistance in hepatic CSCs. As shown in Figure 2D, the resulting Epirubicin@nanodiamonds complex, EPND, possesses enhanced treatment compared with unmodified Epirubicin (Wang et al., 2014). The ability to attach various bioactive molecules, including cell-specific ligands, to carbon molecules enables carbon-based nanomaterials to be an efficient solution for cancer therapy by targeting CSCs.

\section{DNA ORIGAMI FOR TARGETING CSCs}

DNA self-assembling nanostructure (Lanier and Bermudez, 2015; Kim et al., 2016; Xia et al., 2016), especially DNA origami, has been considered as the most promising candidates as a drug delivery carrier for cancer therapy (Zhao et al., 2012; Ouyang et al., 2013; Zhu et al., 2013; Zhang et al., 2014; Jiang et al., 2015; Zhuang et al., 2016). DNA origami were prepared through the self-assembly of a long single stranded M13mp18 phage DNA and hundreds of complementary short DNA staples, which endows the structure with high levels of structural programmability, obvious biocompatibility, and easiness to be modified with functional moieties. Furthermore, DNA origami can be functionalized with the agents of interest with high spatial precision, the so called "addressability." With the aid of this technology, nanoscale assemblies of drugs and other active agents can be organized with unprecedented precision and with high load for targeted therapies.

In 2012, Jiang et al. reported a drug delivery system (Figure 3A) based on triangular and tubular DNA origami nanostructures, which are spatially addressable, of high loading capacity and good biocompatibility. Then, doxorubicin were loaded in these structures and administered to human breast cancer cell line MCF-7 cells and the effective internalization of the structure by both cell lines were confirmed by confocal fluorescent analyses. The origami-doxorubicin complex exhibited prominent cytotoxicity not only to regular human breast cancer cells (MCF 7), but more importantly to doxorubicin-resistant cancer cells, inducing a remarkable reversal of phenotype resistance. Then, the authors studied the means by which the DNA origami-drug complex circumvents resistance in res-MCF 7 cells. The results indicated that the DNA nanostructure delivery platform circumvented drug resistance in res-MCF 7 cells by increasing the cellular uptake of doxorubicin and inducing a change in lysosomal $\mathrm{pH}$ that redistributed the drug to target sites (Jiang et al., 2012). Halley et al. synthesized a rod-like DNA origami drug carrier (Figure 3B) that can be controllably loaded with daunorubicin and demonstrated the ability of the DNA origami-drug complex to circumvent efflux-pump-mediated drug-resistance of leukemia cells. Their results directly showed that DNA origami-based daunorubicin delivery had the potential to treat acute leukemia cells exhibiting multi-drug resistance (MDR). In addition, the results revealed that circumvention of MDR could be achieved at concentration ranges of $0.1-1.0 \mu \mathrm{mol} / \mathrm{L}$ daunorubicin. What's more, they found that it is crucial to control the quantities of drug loaded in origami to maximize the drug efficacy, especially in disrupting cellular proliferation (Halley et al., 2016).

Nowadays, it is simple to synthesize various DNA origamis with a series of geometric and aesthetic shapes (triangle, rectangle, pillar, and so on) with diverse dimensions (1D, 2D, and $3 \mathrm{D}$ ) using rational design principles. In addition, the fully addressable DNA origami nanostructures can be produced in extremely high yields and a wide range of molecules and nanoparticles can be functionalized on the nanostructures through hundreds of addressable staples. What's more, it is suggested that DNA origami were of excellent stability in cell lysate, which is of great significance for drug delivery and controlled drug release. All these properties enable DNA origami structures a promising tool in biomedical fields, especially in cancer nanotechnology. We believe that DNA origami has unlimited potential and will play important roles in cancer therapies in the future.

\section{GOLD NANOPARTICLES FOR TARGETING CSCs}

Gold nanoparticles [e.g., Au NPs and gold nanorods (Au NRs)] have been widely used in cancer research (Wang et al., 2011; 

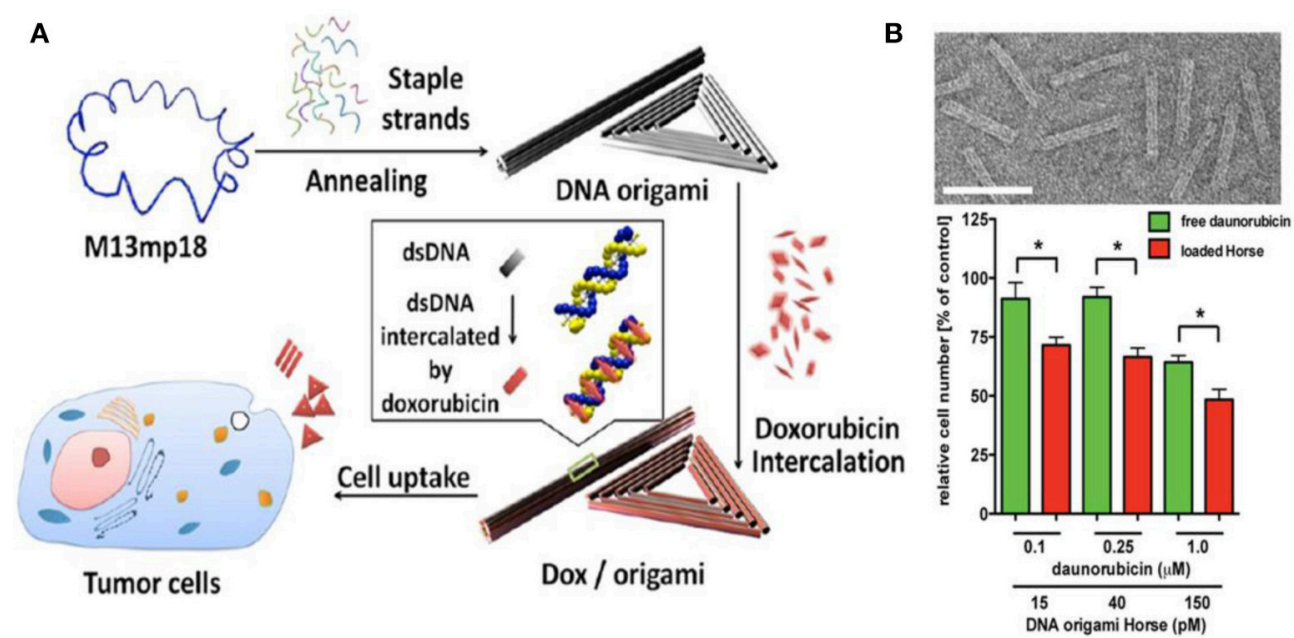

FIGURE 3 | (A) DNA origami and doxorubicin origami delivery system assembly. The long single-strand M13mp18 genomic DNA scaffold strand (blue) is folded into the triangle and tube structures through the hybridization of rationally designed staple strands. Watson-Crick base pairs in the double helices serve as docking sites for doxorubicin intercalation. After incubation with doxorubicin, the drug-loaded DNA nanostructure delivery vessels were administered to human breast cancer cell line MCF 7 cells, and the effects were investigated (Jiang et al., 2012); (B) Top: Transmission electron microscope (TEM) images of the designed DNA origami structure; Bottom: The number of viable cells subjecting to free daunorubicin or daunorubicin-loaded Horse nanostructures for $24 \mathrm{~h}$ (Halley et al., 2016$) .{ }^{\star} p<0.05$.

Chen et al., 2012; Iodice et al., 2016) by the reason of their facile synthesis, easiness for functionalization, localized surface plasmon resonance, and excellent biocompatibility (Huang and El-Sayed, 2010). In fact, it has been well-established that Au NPs are biocompatible (non-cytotoxic and non-immunogenic), which is very important for the widespread applications in nanomedicine and drug delivery (Ghosh et al., 2008; Brown et al., 2010; Kong et al., 2016). All these properties enable them very suitable for clinical research (Lee et al., 2011; Tiloke et al., 2016). Nowadays, sphere Au NPs (Sun and Xia, 2002) of different diameters can be synthesized in high quality and high yield by the well-known citrate reduction method. The progress of synthetic chemistry in the last decade enables Au NPs of different shapes (Murphy et al., 2005; Xia et al., 2009) and sizes to be synthesized, including Au NRs (Jana et al., 2001; Nikoobakht and El-Sayed, 2003), gold nanoflowers (Xie et al., 2008; Wang et al., 2010), gold nanocages (Skrabalak et al., 2008; Xia et al., 2011), and so on. The radiative properties of gold nanoparticles including absorption, scattering and localized surface plasmon resonance (LSPR) make them very suitable for photothermal therapy and molecular cancer imaging. While the easiness for surface modification enables them very suitable for drug delivery (Tian et al., 2016) and cancer therapies.

\section{SPHERE AU NPS}

The unique physico-chemical properties of Au NPs have been used for targeted drug delivery (Ghosh et al., 2008; Elbialy et al., 2015) in almost all cancer types and have demonstrated enhanced anti-tumor efficacy (Patra et al., 2010; Wagstaff et al., 2012; Setua et al., 2014). However, the discovery of CSCs has changed the direction of the targeted chemotherapy and directs the anti-cancer research toward targeting CSCs (Atkinson et al., 2010; Sun et al., 2014a,b; Gilam et al., 2016; Yi et al., 2016).

Tomuleasa et al. reported a novel strategy based on functionalized Au NPs for Hepatocellular carcinoma and lowered the chemoresistance of Hepatocellular Carcinoma Cells. They first stabilized Au NPs with a monolayer of L-aspartate and then additional drugs (e.g., doxorubicin, cisplatin, and capecitabine) were conjugated through non-covalent interaction to obtain the drug complex. Tumor-targeting results suggested that the cellular proliferation in the presence of the anti-cancer drugs complex prepared from the Au NPs were repressed compared with those of cells exposed to the cytostatic drugs alone, indicating that $\mathrm{Au}$ NPs increased the susceptibility of Hepatocellular Carcinoma Cells to these drugs (Tomuleasa et al., 2012). Cancer cells undergo faster metabolism and consume more glucose than normal cells, taking advantage of this property, Hu et al. chose glucose as a reagent to target cancer cells. Au NPs modified with thio-PEG (polyethylene glycol) and thio-glucose (Glu-Au NPs) was created for targeted treatment of cancer metastasis and CSCs. Using human monocytic cell line derived from acute monocytic leukemia patients as a model (due to its properties are similar to CSCs), and then fed the cells with Glu-Au NPs followed by X-ray irradiation. The experimental results show that Glu-Au NPs enhanced the elimination of human monocytic cells 20\% more than X-ray irradiation alone and Au NP treatment alone (Hu et al., 2015). Kouri et al. synthesized Au NPs modified with mature miR-182 duplexes [miR-182based spherical nucleic acids (182-SNAs), Figure 4A] and injected 182-SNAs intravenously to the orthotopic Glioblastoma multiforme (GBM) xenografts. The results showed that 182SNAs could penetrate the blood-brain/blood-tumor barriers and selectively disseminate throughout extravascular glioma parenchyma, leading to shrinked tumor size and increased 

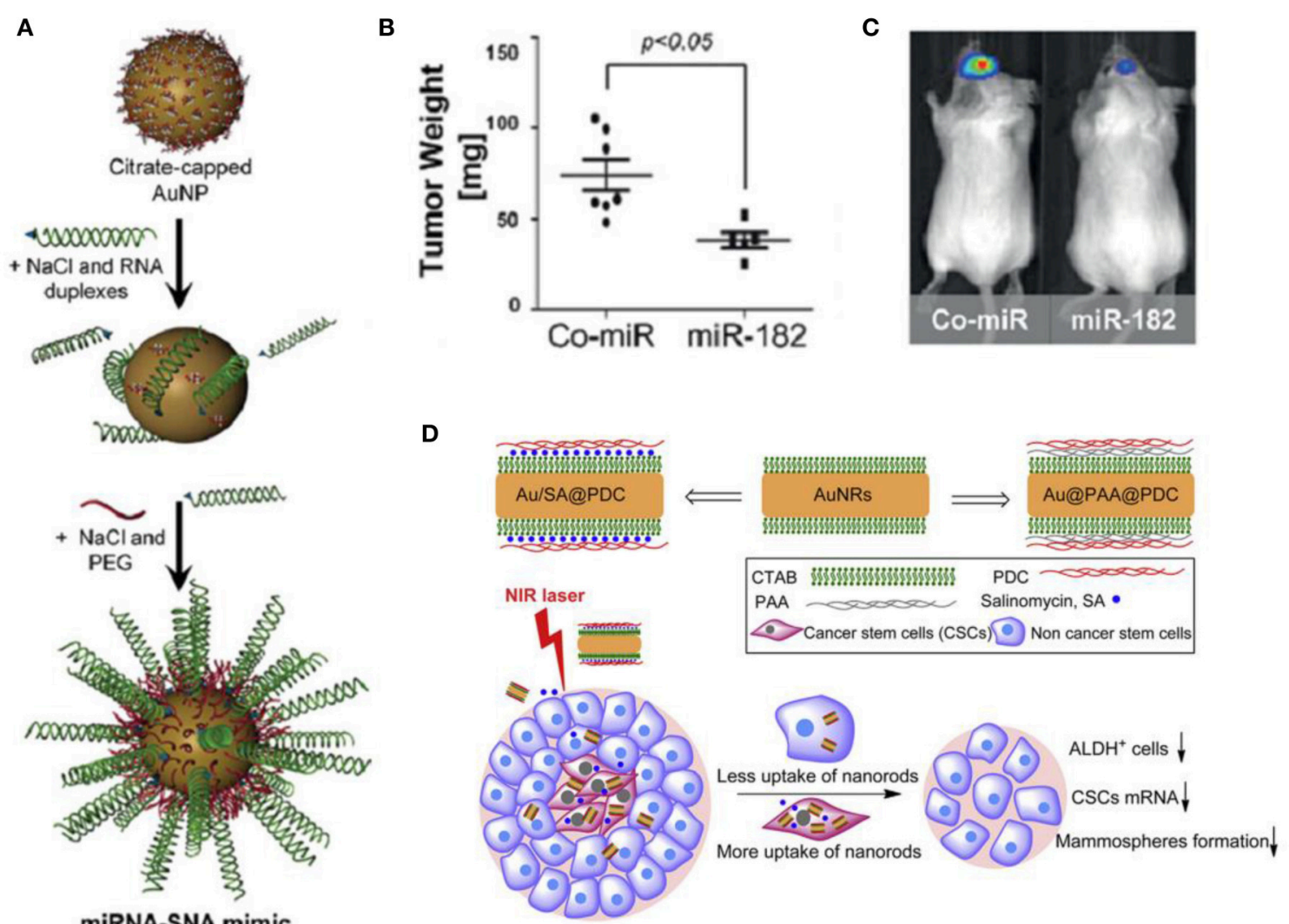

FIGURE 4 | (A) miR-182 or Co-miR-RNA duplexes were hybridized to citrate stabilized gold nanoparticles (Au NPs) via thiol-gold bond and passivated with polyethylene glycol-Thiol (mPEG-SH) to obtain miR-182-based spherical nucleic acids (182-SNAs); (B) Analysis of tumor burden by weight and (C) bioluminescence imaging; (A-C) (Kouri et al., 2015); (D) Top: fabrication of polyelectrolyte conjugated Au NRs and drug loading; Bottom: schematic illustration of selective elimination of breast cancer stem cells (CSCs) by polyelectrolyte conjugated gold nanorods (Au NRs) mediated hyperthermia. CTAB, cetyltriethylammnonium bromide; PAA, Poly(acrylic acid); PDC, poly-diallyldimethylammonium chloride; $\mathrm{ALDH}^{+}$, aldehyde dehydrogenase positive (Xu et al., 2014).

survival rates (Figures $4 \mathrm{~B}, \mathrm{C}$ ). The authors, here, present a novel strategy for therapeutic intervention in GBM by exploiting the anti-tumor activities of miR-182 which was modified on Au NPs to form spherical nucleic acids (Kouri et al., 2015).

\section{GOLD NANORODS (AU NRs)}

Compared with Au NPs, Au NRs have greater advantages in cancer cell imaging and photothermal therapy based on their localized surface plasmon resonance (LSPR) at near-infrared (NIR) wavelength band (Oli, 2010; Peng and Wang, 2011). One of the advantages of $\mathrm{Au}$ NRs is that the light source used for imaging and photothermal therapy can be NIR wavelength band which induce less damage and possess better tissue penetrability. Therefore, $\mathrm{Au}$ NRs has been widely used in cancer research, especially in photothermal therapy (Amreddy et al., 2015; Liu et al., 2016).

Wang et al. reported a strategy by using aptamer-modified $\mathrm{Au}$ NRs for targeted photothermal therapy of prostate CSCs. In this work, two kinds of aptamers [against DU145 prostate cancer cells (aptamer CSC1) and against prostate CSCs (aptamer
CSC13)] were modified on the surfaces of Au NRs, and the obtained Au NRs complex successfully targeted and destructed both cancer cells and CSCs through NIR laser irradiation (Wang et al., 2013). Xu et al. found that photothermal therapy mediated by $\mathrm{Au}$ NRs can selectively eliminate breast CSCs (Xu et al., 2014). The results suggested that polyelectrolyte conjugated $\mathrm{Au}$ NRs treatment reduced the aldehyde dehydrogenase positive (ALDHp) cells subpopulation, the gene expression of stem cell markers and the mammosphere forming ability. Cellular uptake assay suggested that one of the possible reasons for the selective elimination of CSCs is they could internalize much more and faster of the conjugated Au NRs. The authors further combined the chemotherapy and photothermal therapy, loading the polyelectrolyte conjugated Au NRs with salinomycin (SA), and obtained enhanced inhibition of CSCs (Figure 4D).

The combination of multiple therapies for cancer treatment has already been inevitable and is also a general tendency. The development and integration of materials science, bioimaging, and cancer biology has now enabled the design of stimuliresponsive intelligent platforms for cancer therapies (Conde et al., 2015). In 2016, Conde et al. developed a triple-integration therapy, a combination of gene therapy, drug therapy and 
photothermal therapy, to remit non-resected tumor, and prevent tumor recurrence after the tumor excision surgery (Conde et al., 2016). They loaded hydrogel with Au NRs@drug (for chemotherapy and photothermal therapy) and Au NPs@siRNA (for Kras gene silencing) for triple therapies (Figure 5A), while the hydrogel was used to stabilize the integral delivery system and enable local delivery of the conjugates. In the same year, Kong et al. prepared a biocompatible double emulsion system with higher integration degree, which integrated porous silicon nanoparticles (PSi NP), Au NRs, DNA origami, antibody, doxorubicin, 17-AAG or Rapamycin, and Erlotinib or Afatinib in one platform; (Kong et al., 2016; Figure 5B). The all-in-one system could overcome multidrug resistance and enable more effective treatments of cancer, thus it holds great potential in biomedical field for cancer therapy.

$\mathrm{Au}$ NPs are potential nanomaterials to be utilized in CSCs targeting for the following reasons: firstly, they can be easily synthesized a wide variety of sizes and shapes; secondly, they are very stable, of highly biocompatibility and easily to be functionalized with various bioactive agents; Thirdly, they possess unique optical properties and are easily tracked and detected by absorption/scattering spectroscopy.

\section{ORGANIC NANOPARTICLES FOR TARGETING CSCs}

Liposomes, polymeric nanoparticles, and dendrimers have been the most widely studied carriers in the field of nanoscale drug delivery (Duncan and Gaspar, 2011). Why they are so popular? First, they hold high stability and good biocompatibility both in vitro and in vivo, and can solubilize a wide range of poorly soluble drugs. Polymeric nanoparticles are commonly prepared from natural polymers (such as chitosan) or synthetic biocompatible polymers [such as poly-lactic-coglycolic acid (PLGA)], while liposomes, analogs of biological membranes, have always been regarded as one of the most biocompatible vehicles for drug delivery (Colson and Grinstaff, 2012; Hadinoto et al., 2013; Mandal et al., 2013; Crucho, 2015). In addition, polyethylene glycol (PEG) is usually conjugated to the polymer nanoparticles to enhance the immune-compatibility. Second, they can avoid the short time drug degradation after administration. Third, they can also prevent undesirable side effects on normal cells, organs, and tissues by some cytotoxic drugs. The last but not the least, they can increase drug bioavailability and the fraction of the drug accumulated in the pathological area. A variety of drug delivery and drug targeting systems, such as synthetic polymers(Chenna et al., 2012; Usacheva et al., 2014; Kumar et al., 2015), microcapsules (Chen et al., 2015), lipoproteins (Helbok et al., 2012; Shen et al., 2016), liposomes (Yuan et al., 2013; Han et al., 2014; Lokerse et al., 2016), lipid particles(You et al., 2015), and many others have been designed and exploited for cancer therapy (Torchilin, 2006). Therefore, they hold great potential to generate practical strategies for the CSC therapy in the near future.

\section{LIPOSOME}

A liposome is a spherical vesicle that composed of at least one lipid bilayer and it can be used as a vehicle for delivering drugs. Liposomes can ameliorate the stability and pharmacokinetics of free drugs and furthermore improve the safety and efficiency of them, but the therapeutic efficacy of them has not been sufficiently enhanced. Compared with non-targeted liposome, targeted treatment of cancer cells, especially the CSCs, do hold

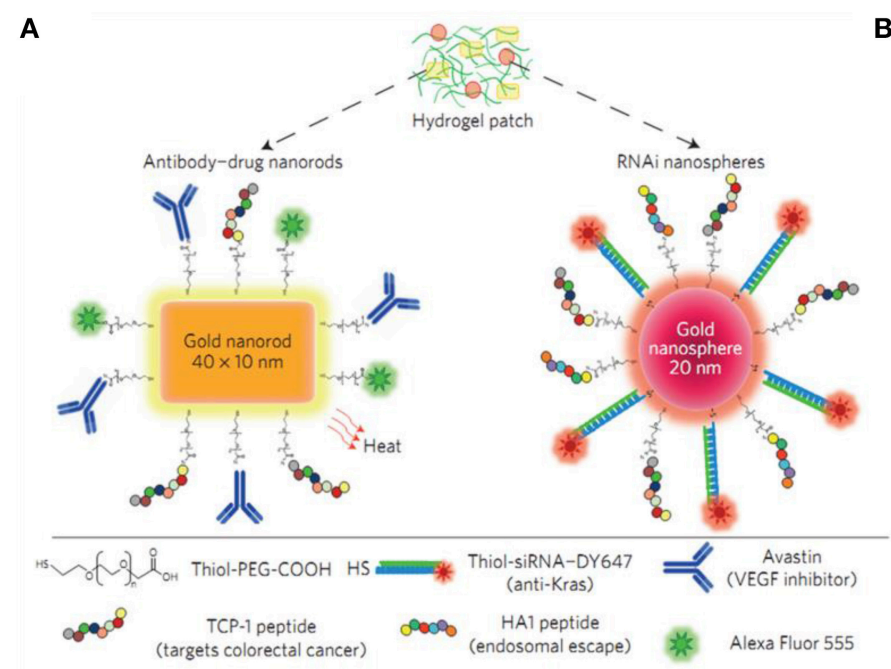

B

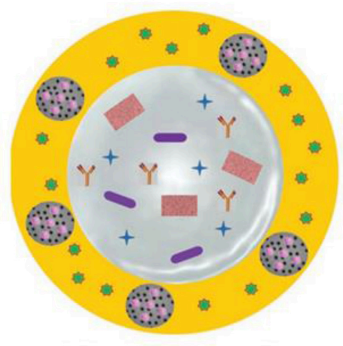

w/o/w double emulsion

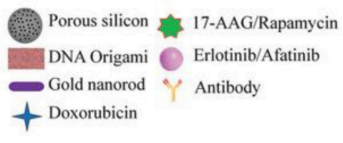

FIGURE 5 | (A) Drug-gold nanorods and siRNA-gold nanospheres doped in implantable hydrogels for local drug/gene delivery and local hyperthermia (Conde et al., 2016). (B) Schematic illustration of the preparation of biocompatible porous silicon nanoparticles@gold nanorods@double emulsion (PSi NPs@AuNRs@double emulsion) co-delivery platform for co-loading versatile therapeutics, DNA origami, antibody, and hydrophobic functional PSi NPs loaded with Erlotinib or Afatinib (Kong et al., 2016). 


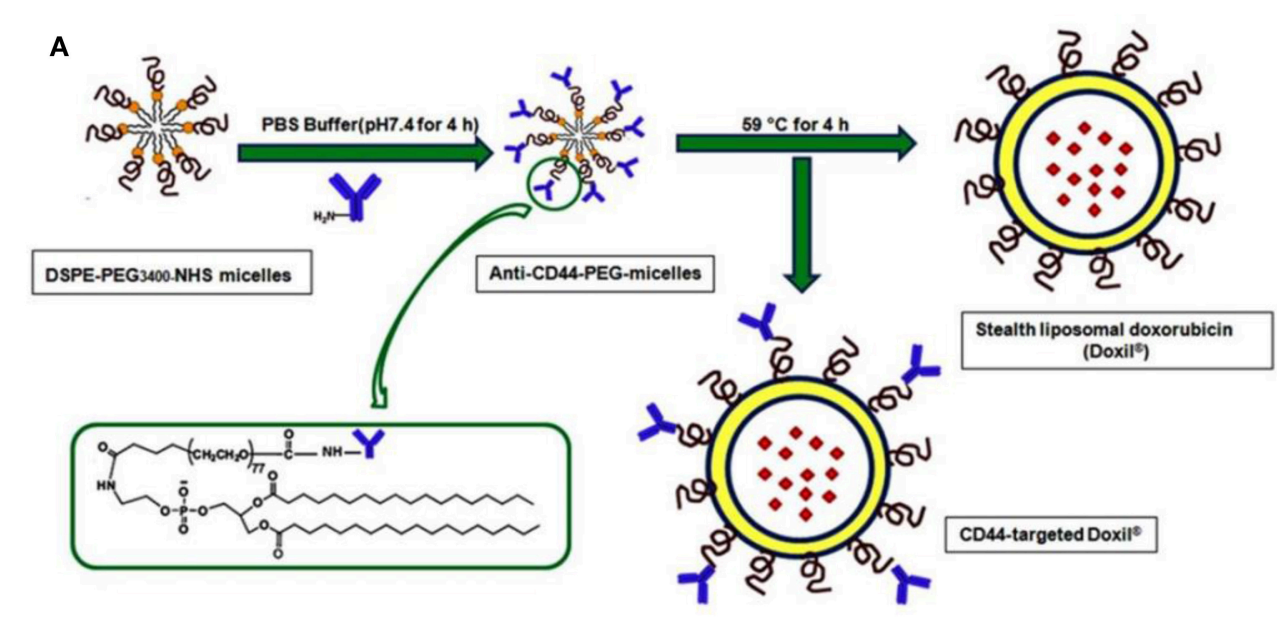

B
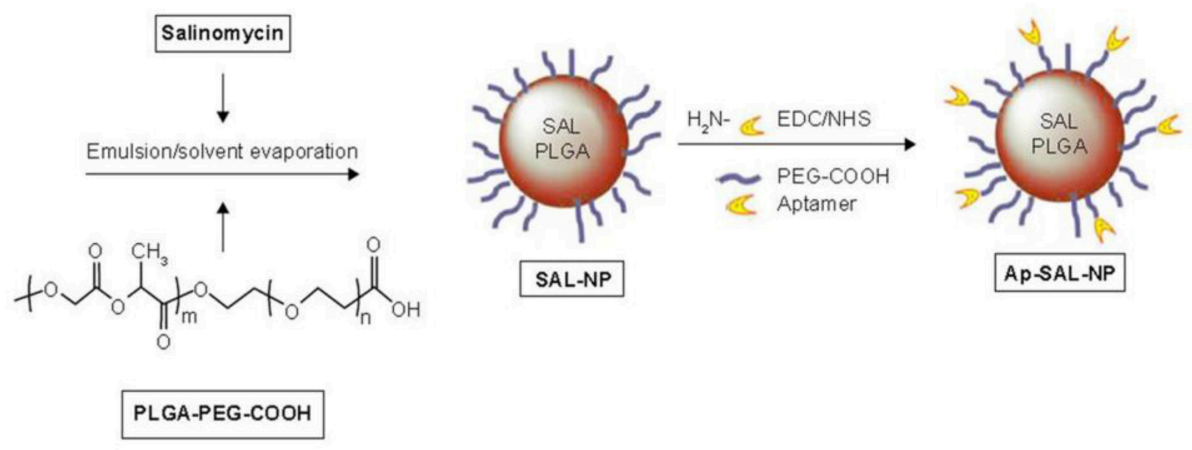

FIGURE 6 | (A) Post-insertion method for the preparation of CD44-doxil (Arabi et al., 2015). (B) The preparation procedure of salinomycin-loaded PEGylated poly(lactic-co-glycolic acid) nanoparticles (SAL-NP) or SAL-NP linked with CD133 aptamers (Ap-SAL-NP; Ni et al., 2015).

great potential to improve the therapeutic index, and decrease the influence of off-target phenomenon.

Liu et al. first synthesized a liposome involving antialcoholism drug disulfiram (shorted for lipo-DS) combined with copper in vivo, aiming to target CSCs and avoid pan-chemoresistance (Liu et al., 2014). Lipo-DS targeted NFאB pathway, that promote hypoxia-induced CSCs and these fabricated LipoDS/CuGlu (copper gluconate) showed a strong anti-CSC efficacy. In the following year, Shen et al. fabricated a novel Nano-Taxol (encapsulated paclitaxel in liposome), and then investigated its effects on the stem ness phenotype and metabolic reprogramming of CSC (Shen et al., 2015). They found that intraperitoneal administration of Nano-Taxol influenced the metabolic reprogramming of cells, from glycolysis to oxidative phosphorylation and effectively suppressed CSCs. Compared with intravenous delivery of Taxol? (current standard treatment), Nano-Taxol showed a significantly better control of tumor growth. This research may provide a new approach for the nanomedicine development. In the near future, this method can be applied to the treatment of several relevant cancers that have been proved to be suitable for local delivery of therapeutic agents, including colon cancer, gastric cancer, and pancreatic cancer. In 2015, Basak et al. demonstrated that delivery of Curcumin-difluorinated (CDF) liposomes was a useful method for cisplatin resistant Head and neck squamous cell carcinoma (HNSCC) therapy (Basak et al., 2015). CDF, synthesized from the curcumin and wrapped with liposomes, was applied to evaluate the growth inhibition of cisplatin resistant HNSCC cell lines CCL-23R and UM-SCC-1R, and showed significant growth inhibition in these drug-resistant cell lines. Then, Arabi et al. constructed monoclonal antibody (mAb) modified doxil (Figure 6A), which would not damage the biodistribution of a long-circulating carrier, and used it to target CD44, one of the most well-known surface markers related with CSCs. The result indicated the potential of anti-CD44 mAb in the improvement CSC therapy (Arabi et al., 2015). 
ANV-1 was a liposomal formulation for carrying anticancer drug to breast cancer stem-cell-like cells, and its pharmacokinetics in an animal model also had been evaluated. The anticancer drug ESC8 connected with dexamethasone (Dex)-associated liposome (DX) to form ESC8-entrapped liposome named DXE. The results showed DXE was a promising liposomal formulation with potent pharmacokinetic and tumor regressing profile that could sensitize and kill highly aggressive and drug-resistive tumor progenitor cells (Ahmad et al., 2016). Since liposomes provide a biocompatible and biodegradable container for loading drugs and the surface of which can be modified with various targeting ligand, they hold great possibility to deliver drugs for targeted cancer therapy.

\section{POLYMER NANOPARTICLES}

Targeting cancer metabolism is emerging as a successful strategy for cancer therapy. In 2012, Xu et al. constructed NanoHHI (nanoparticle-encapsulated inhibitor of the hedgehog transcription factor) by the oil-in-water $(\mathrm{o} / \mathrm{w})$ emulsion solvent evaporation method that loaded PLGA-PEG (poly(lactic-coglycolic acid) - polyethylene glycol) nanoparticles with HPI1 (Xu et al., 2012). NanoHHI significantly suppressed the growth of both Huh7 and MHCC97L cells, decreased the population of CD133-positive hepatocellular carcinoma cells (HCC). Thioridazine (THZ), which was reported to have ability to kill CSCs, was combined with doxorubicin (DOX) to eradicate both cancer cells and DOX-resistant CSCs to mitigate the cancer relapse (Ke et al., 2014). The micelles were self-assembled from a mixture of acid-functionalized poly (carbonate) and poly(ethylene glycol) diblock copolymer (PEGPAC) and urea-functionalized poly(carbonate) (PUC) and PEG diblock copolymer (PEG-PUC). Co-delivery of free DOX and THZ with the micelles showed strong inhibitory effect against cancer cells and CSCs. This combination therapy can target both cancer cells and CSCs offered a favorable strategy for breast cancer therapy. In 2015, Ni et al. developed nomycinloaded nanoparticles to eliminate CD133+ osteosarcoma CSCs (Ni et al., 2015). Then, salinomycin-loaded PEGylated poly (lactic-co-glycolic acid) nanoparticles (SAL-NP) connected with CD133 aptamers (Ap-SAL-NP) (Figure 6B) were constructed by the method of emulsion/solvent evaporation. The results suggested that CD133, a well-known surface marker in CSCs, was a prospective target for drug delivery to osteosarcoma CSCs and that it is potential to significantly inhibit the osteosarcoma growth by killing CD133+ osteosarcomal CSCs.

In 2013, Swaminathan et al. synthesized poly(D,L lactide-coglycolide) nanoparticles modified with anti-CD133 monoclonal antibody and paclitaxel, a microtubule-stabilizing anticancer agent, to target CD133 + cells (Swaminathan et al., 2013). CD133targeted nanoparticles (CD133NPs) were effectively engineered to target cells which abundantly express CD133, and the NPs show significant suppression of Caco-2 cells, decreasing the number of mammospheres and colonies formed compared with the free paclitaxel treatment. Nanogel-drug conjugates based on membranotropic cholesteryl-HA (CHA) were also developed by Wei et al. for efficient targeting and suppressing drug-resistant tumors (Wei et al., 2013). The conjugates significantly increased the solubility and bioactivities of poorly soluble drugs, such as etoposide, salinomycin, and curcumin against CSC. These nanogels were efficiently internalized via CD44 receptor and was shown to be capable of penetrate multicellular cancer spheroids and displayed higher cytotoxic effect in the system modeling tumor environment than both free drugs and HAdrug conjugates. Cationic lipid-assisted poly(ethylene glycol)b-poly(d,L-lactide) (PEG-PLA) nanoparticles, can efficiently deliver siRNA into U87MG and U251 glioma stem cells and bulk glioma cells, simultaneously inhibited the selfrenewal of these cells in a glucose restricted tumor microenvironment. PEG-PLA Nanoparticles with specific siRNA targeting GLUT3 (NPsiGLUT3) significantly reduced the GLUT3 expression in glioma stem cells and bulk glioma cells, and also inhibited the metabolism, proliferation, and downregulated further glioma stem cells percentage (Xu C. F. et al., 2015). Because of the diversity of organic nanoparticles and the tunability of their properties, they have been exploited extensively for cancer therapies and will play a bigger role in the future.

\section{SUMMARY AND OUTLOOK}

CSCs, also called as cancer- (or tumor-) initiating cells, are not only a grand challenge in cancer therapy, but also a great opportunity for researchers to overcome cancer. CSCs have been regarded as one of the most possible reasons for the inefficiency or failure (recurrence and metastasis) of current cancer therapies, which can be mainly ascribed to the multidrug resistance, dormancy and resistance to apoptosis properties of these cells. All these properties enable them obvious and challenging targets for improving the present therapeutic approaches. Despite the challenges, much effort has been devoted to selectively target CSCs. A wide spectrum of materials, such as carbon, DNA, metal, polymer has been used in cancer therapy by targeting CSCs as summarized in Table 1. Each of these materials has its own unique properties, such as high levels of structural programmability and addressability of DNA origami, stability, and tunable optical properties of Au NPs, Electro-conductivity and large surface area of grapheme and diversity of polymer NPs, combine several of these materials and take advantage of these properties will provide better solutions for the targeted and controlled destruction of CSCs.

The biological structures and functionalities of cancer cells, especially CSCs, are very complicated, thus it is essential to explore the exact mechanisms, to further understand their cell biology, and, most importantly, to find biomarkers and pathways for the specific targeting and destructing the CSCs. In a word, the ultimate goal of CSC research is to identify effective targeting biomarkers, delivering pathways, and therapeutics that can eliminate CSCs of various cancers, which may be realized by combining advances in cell biology of CSC and progress in nanotechnologies. In the future, multifunctional nanosystems 
TABLE 1 | The list of nanoparticles targeting CSC.

\begin{tabular}{|c|c|c|c|c|c|}
\hline \multicolumn{2}{|l|}{ Type of nanoparticles } & \multirow{2}{*}{$\begin{array}{l}\text { Targets } \\
\text { Six independent } \\
\text { cancer cell lines, } \\
\text { HA receptors }\end{array}$} & \multirow{2}{*}{$\begin{array}{l}\text { Anticancer agent } \\
\text { Nanographene oxide, nanographene } \\
\text { oxide-Hyaluronic acid }\end{array}$} & \multirow{2}{*}{$\begin{array}{l}\text { Type of cancer } \\
\text { Breast cancer, ovarian cancer, } \\
\text { prostate cancer, lung cancer, } \\
\text { pancreatic cancer, brain cancer, } \\
\text { melanoma skin cancer }\end{array}$} & \multirow{2}{*}{$\begin{array}{l}\text { References } \\
\text { Jung et al., 2014; } \\
\text { Fiorillo et al., } 2015\end{array}$} \\
\hline Carbon nanomaterials & Graphene oxide & & & & \\
\hline & Carbon nanotubes & $\begin{array}{l}\text { HA receptors, } \\
\text { CD44 }\end{array}$ & $\begin{array}{l}\text { Carbon nanotube, } \\
\text { Paclitaxel/SAL(salinomycin)- } \\
\text { SWNT(single wall } \\
\text { carbon nanotubes)-CHI(chitosan)- } \\
\text { HA(hyaluronic } \\
\text { acid) }\end{array}$ & $\begin{array}{l}\text { Breast cancer stem cells, gastric } \\
\text { cancer stem cells }\end{array}$ & $\begin{array}{l}\text { Yao et al., 2014; Al } \\
\text { Faraj et al., 2016a,b }\end{array}$ \\
\hline & Nanodiamond & None & $\begin{array}{l}\text { Nanodiamond with hyperbranched } \\
\text { polyglycerol with anticancer drug } \\
\text { (dND-PG-Anticancer drug), } \\
\text { Epirubicin@nanodiamonds(EPND) }\end{array}$ & Hepatic cancer stem cells & $\begin{array}{l}\text { Wang et al., 2014; } \\
\text { Zhao et al., } 2014\end{array}$ \\
\hline DNA origami & Triangle, tube etc. & None & $\begin{array}{l}\text { Doxorubicin-DNA nanostructure delivery } \\
\text { platform, rod-like DNA origami } \\
\text { daunorubicin carrier }\end{array}$ & $\begin{array}{l}\text { Human breast cancer cells (MCF 7), } \\
\text { doxorubicin-resistant cancer cells, } \\
\text { leukemia cells exhibiting multi-drug } \\
\text { resistance (MDR) }\end{array}$ & $\begin{array}{l}\text { Jiang et al., 2012; } \\
\text { Halley et al., } 2016\end{array}$ \\
\hline \multirow[t]{2}{*}{ Gold nanoparticles } & Sphere Au NPs & None & $\begin{array}{l}\text { Monolayer L-aspartate Au NPs with drugs, } \\
\text { Au NPs modified with thio-PEG } \\
\text { (polyethylene glycol) and thio-glucose } \\
\text { (Glu-Au NPs), Au NPs modified with } \\
\text { mature miR-182 duplexes }\end{array}$ & $\begin{array}{l}\text { Hepatocellular carcinoma, cancer } \\
\text { metastasis and cancer stem cells, } \\
\text { Glioblastoma multiforme (GBM) }\end{array}$ & $\begin{array}{l}\text { Tomuleasa et al., } \\
\text { 2012; Hu et al., } \\
\text { 2015; Kouri et al., } \\
2015\end{array}$ \\
\hline & Gold nanorods & $\begin{array}{l}\text { TGF- } \beta \text {, } \\
\text { acid-liable, } \\
\text { ALDH }\end{array}$ & $\begin{array}{l}\text { Polyelectrolyte conjugated Au NRs with } \\
\text { salinomycin (SA) }\end{array}$ & $\begin{array}{l}\text { Aldehyde dehydrogenase positive } \\
\text { (ALDHP) cells }\end{array}$ & $\begin{array}{l}\text { Wang et al., 2013; } \\
\text { Xu et al., } 2014\end{array}$ \\
\hline \multirow[t]{2}{*}{ Organic nanoparticles } & Liposome & $\begin{array}{l}\text { NFкB pathway, } \\
\text { CCL-23R, } \\
\text { UM-SCC-1R, } \\
\text { CD44 }\end{array}$ & $\begin{array}{l}\text { Lipo-DS/CuGlu, Nano-Taxol, } \\
\text { Curcumin-difluorinated (CDF) liposomes, } \\
\text { monoclonal antibody (mAb) modified doxil, } \\
\text { ESC8 dexamethasone liposome (DXE) }\end{array}$ & $\begin{array}{l}\text { Colon cancer, gastric cancer, } \\
\text { pancreatic cancer, cisplatin resistant } \\
\text { Head and neck squamous cell } \\
\text { carcinoma (HNSCC), breast cancer } \\
\text { stem-cell, aggressive and } \\
\text { drug-resistive tumor progenitor cells }\end{array}$ & $\begin{array}{l}\text { Liu et al., 2014; } \\
\text { Arabi et al., 2015; } \\
\text { Basak et al., 2015; } \\
\text { Shen et al., 2015; } \\
\text { Ahmad et al., 2016 }\end{array}$ \\
\hline & Polymer nanoparticles & CD133+, CD44 & $\begin{array}{l}\text { Nanoparticle-encapsulated inhibitor of the } \\
\text { hedgehog transcription factor(NanoHHI), } \\
\text { acid-functionalized poly(carbonate) and } \\
\text { poly(ethylene glycol) diblock copolymer } \\
\text { (PEG-PAC) and urea-functionalized } \\
\text { poly(carbonate) (PUC) and PEG diblock } \\
\text { copolymer (PEG-PUC), CD133-targeted } \\
\text { nanoparticles (CD133NPs), Cationic } \\
\text { lipid-assisted poly(ethylene } \\
\text { glycol)-b-poly(d,L-lactide) (PEG-PLA) } \\
\text { nanoparticles with specific siRNA targeting } \\
\text { GLUT3 (NPsiGLUT3) }\end{array}$ & $\begin{array}{l}\text { Huh7 and MHCC97L cells, } \\
\text { hepatocellular carcinoma cells (HCC), } \\
\text { doxorubicin resistant cancer stem } \\
\text { cells, CD133+ cells, Caco-2 cells, } \\
\text { U87MG and U251 glioma stem cells } \\
\text { and bulk glioma cells }\end{array}$ & $\begin{array}{l}\text { Xu et al., 2012; } \\
\text { Swaminathan et al., } \\
\text { 2013; Wei et al., } \\
\text { 2013; Ke et al., } \\
\text { 2014; Ni et al., } \\
\text { 2015; Xu C. F. et al., } \\
2015\end{array}$ \\
\hline
\end{tabular}

would be a solution for the early detection and destruction of CSCs.

\section{AUTHOR CONTRIBUTIONS}

WQ and GH wrote the manuscirpt, $\mathrm{ZC}$ and $\mathrm{YZ}$ revised the manuscript. WQ and GH contributed equally to this review.

\section{REFERENCES}

Ahmad, A., Mondal, S.K., Mukhopadhyay, D., Banerjee, R., Alkharfy, K. M. (2016). Development of liposomal formulation for delivering anticancer drug to breast

\section{FUNDING}

This work was supported by the National Natural Science Foundation of China (Nos. 81601571, 31370868 and 21375152), a Start-up Grant from Sun Yat-Sen University and the Fundamental Research Funds for the Central Universities (No. 16ykzd13).

cancer stem-cell-like cells and its pharmacokinetics in an animal model. $\mathrm{Mol}$. Pharm. 13, 1081-1088. doi: 10.1021/acs.molpharmaceut.5b00900

Al Faraj, A., Shaik, A. S., Al, Sayed, B., Halwani, R., and Al, Jammaz, I. (2016a). Specific targeting and noninvasive imaging of breast cancer stem 
cells using single-walled carbon nanotubes as novel multimodality nanoprobes. Nanomedicine 11, 31-46. doi: 10.2217/nnm.15.182

Al Faraj, A., Shaik, A. S., Ratemi, E., and Halwani, R. (2016b). Combination of drug-conjugated SWCNT nanocarriers for efficient therapy of cancer stem cells in a breast cancer animal model. J. Control. Release 225, 240-251. doi: 10.1016/j.jconrel.2016.01.053

Al-Hajj, M., Wicha, M. S., Benito-Hernandez, A., Morrison, S. J., and Clarke, M. F. (2003). Prospective identification of tumorigenic breast cancer cells. Proc. Natl. Acad. Sci. U.S.A. 100, 3983-3988. doi: 10.1073/pnas.0530291100

Amreddy, N., Muralidharan, R., Babu, A., Mehta, M., Johnson, E. V., Zhao, Y. D., et al. (2015). Tumor-targeted and pH-controlled delivery of doxorubicin using gold nanorods for lung cancer therapy. Int. J. Nanomed. 10, 6773-6788. doi: $10.2147 /$ IJN.S93237

Arabi, L., Badiee, A., Mosaffa, F., and Jaafari, M. R. (2015). Targeting CD44 expressing cancer cells with anti-CD44 monoclonal antibody improves cellular uptake and antitumor efficacy of liposomal doxorubicin. J. Control. Release 220, 275-286. doi: 10.1016/j.jconrel.2015.10.044

Atkinson, R. L., Zhang, M., Diagaradjane, P., Peddibhotla, S., Contreras, A., Hilsenbeck, S. G., et al. (2010). Thermal enhancement with optically activated gold nanoshells sensitizes breast cancer stem cells to radiation therapy. Sci. Transl. Med. 2, 55ra79. doi: 10.1126/scitranslmed.3001447

Bao, S., Wu, Q., McLendon, R. E., Hao, Y., Shi, Q., Hjelmeland, A. B., et al. (2006). Glioma stem cells promote radioresistance by preferential activation of the DNA damage response. Nature 444, 756-760. doi: 10.1038/nature05236

Basak, S. K., Zinabadi, A., Wu, A. W., Venkatesan, N., Duarte, V. M., Kang, J. J., et al. (2015). Liposome encapsulated curcumin-difluorinated (CDF) inhibits the growth of cisplatin resistant head and neck cancer stem cells. Oncotarget 6, 18504-18517. doi: 10.18632/oncotarget.4181

Bild, A. H., Yao, G., Chang, J. T., Wang, Q., Potti, A., Chasse, D., et al. (2006). Oncogenic pathway signatures in human cancers as a guide to targeted therapies. Nature 439, 353-357. doi: 10.1038/nature04296

Bonnet, D., and Dick, J. E. (1997). Human acute myeloid leukemia is organized as a hierarchy that originates from a primitive hematopoietic cell. Nat. Med. 3, 730-737. doi: 10.1038/nm0797-730

Brannon-Peppas, L., and Blanchette, J. O. (2004). Nanoparticle and targeted systems for cancer therapy. Adv. Drug Deliv. Rev. 56, 1649-1659. doi: 10.1016/j.addr.2004.02.014

Brown, S. D., Nativo, P., Smith, J.-A., Stirling, D., Edwards, P. R., Venugopal, B., et al. (2010). Gold nanoparticles for the improved anticancer drug delivery of the active component of oxaliplatin. J. Am. Chem. Soc. 132, 4678-4684. doi: $10.1021 /$ ja 908117 a

Burke, A. R., Singh, R. N., Carroll, D. L., Wood, J. C. S., D’Agostino, R. B. Jr, Ajayan, P. M., et al. (2012). The resistance of breast cancer stem cells to conventional hyperthermia and their sensitivity to nanoparticle-mediated photothermal therapy. Biomaterials 33, 2961-2970. doi: 10.1016/j.biomaterials.2011.12.052

Chen, J., Liu, Q., Xiao, J., and Du, J. (2015). EpCAM-antibody-labeled noncytotoxic polymer vesicles for cancer stem cells-targeted delivery of anticancer drug and siRNA. Biomacromolecules 16, 1695-1705. doi: 10.1021/acs.biomac.5b00551

Chen, T., Xu, S., Zhao, T., Zhu, L., Li, Y., Zhang, H., et al. (2012). Gold nanoclusterconjugated amphiphilic block copolymer for tumor-targeted drug delivery. ACS Appl. Mat. Interfaces 4, 5766-5774. doi: 10.1021/am301223n

Chen, Y. C., Huang, X. C., Luo, Y. L., Chang, Y. C., Hsieh, Y. Z., and Hsu, H. Y. (2013). Non-metallic nanomaterials in cancer theranostics: a review of silicaand carbon-based drug delivery systems. Sci. Technol. Adv. Mater. 14:44407. doi: 10.1088/1468-6996/14/4/044407

Chenna, V., Hu, C., Pramanik, D., Aftab, B. T., Karikari, C., Campbell, N. R., et al. (2012). A polymeric nanoparticle encapsulated small-molecule inhibitor of hedgehog signaling (NanoHHI) bypasses secondary mutational resistance to smoothened antagonists. Mol. Cancer Ther. 11, 165-173. doi: 10.1158/1535-7163.MCT-11-0341

Collins, A. T., Berry, P. A., Hyde, C., Stower, M. J., and Maitland, N. J. (2005). Prospective identification of tumorigenic prostate cancer stem cells. Cancer Res. 65, 10946-10951. doi: 10.1158/0008-5472.CAN-05-2018

Colson, Y. L., and Grinstaff, M. W. (2012). Biologically responsive polymeric nanoparticles for drug delivery. Adv. Mater. 24, 3878-3886. doi: 10.1002/adma.201200420
Conde, J., Oliva, N., and Artzi, N. (2015). Implantable hydrogel embedded dark-gold nanoswitch as a theranostic probe to sense and overcome cancer multidrug resistance. Proc. Natl. Acad. Sci. U.S.A. 112, E1278-E1287. doi: 10.1073 /pnas.1421229112

Conde, J., Oliva, N., Zhang, Y., and Artzi, N. (2016). Local triple-combination therapy results in tumour regression and prevents recurrence in a colon cancer model. Nat. Mater. 15, 1128-1138. doi: 10.1038/nmat4707

Crucho, C. I. (2015). Stimuli-responsive polymeric nanoparticles for nanomedicine. ChemMedChem 10, 24-38. doi: $10.1002 / \mathrm{cmdc} .201402290$

Dean, M., Fojo, T., and Bates, S. (2005). Tumour stem cells and drug resistance. Nat. Rev. Cancer 5, 275-284. doi: 10.1038/nrc1590

Diao, J. J., and Cao, Q. (2011). Gold nanoparticle wire and integrated wire array for electronic detection of chemical and biological molecules. AIP Adv. 1, 012115. doi: $10.1063 / 1.3568815$

Diehn, M., and Clarke, M. F. (2006). Cancer stem cells and radiotherapy: new insights into tumor radioresistance. J. Natl. Cancer Inst. 98, 1755-1757. doi: 10.1093/jnci/djj505

Duncan, R., and Gaspar, R. (2011). Nanomedicine(s) under the microscope. Mol. Pharm. 8, 2101-2141. doi: 10.1021/mp200394t

Elbialy, N. S., Fathy, M. M., and Khalil, W. M. (2015). Doxorubicin loaded magnetic gold nanoparticles for in vivo targeted drug delivery. Int. J. Pharm. 490, 190-199. doi: 10.1016/j.ijpharm.2015.05.032

Eramo, A., Lotti, F., Sette, G., Pilozzi, E., Biffoni, M., Di Virgilio, A., et al. (2007). Identification and expansion of the tumorigenic lung cancer stem cell population. Cell Death Differ. 15, 504-514. doi: 10.1038/sj.cdd.4402283

Eyler, C. E., and Rich, J. N. (2008). Survival of the fittest: cancer stem cells in therapeutic resistance and angiogenesis. J. Clin. Oncol. 26, 2839-2845. doi: 10.1200/JCO.2007.15.1829

Fiorillo, M., Peiris-Pagés, M., Ozsvari, B., Gandara, R., Sotgia, F., Lisanti, M. P., et al. (2015). Graphene oxide selectively targets cancer stem cells, across multiple tumor types: implications for non-toxic cancer treatment, via "differentiation-based nano-therapy". Oncotarget 6, 3553-3562. doi: 10.18632 /oncotarget.3348

Fukuda, K., Saikawa, Y., Ohashi, M., Kumagai, K., Kitajima, M., Okano, H., et al. (2009). Tumor initiating potential of side population cells in human gastric cancer. Int. J. Oncol. 34, 1201-1207. doi: 10.3892/ijo_00000248

Galli, R., Binda, E., Orfanelli, U., Cipelletti, B., Gritti, A., De Vitis, S., et al. (2004). Isolation and characterization of tumorigenic, stem-like neural precursors from human glioblastoma. Cancer Res. 64, 7011-7021. doi: 10.1158/0008-5472.CAN-04-1364

Garcia-Barros, M., Paris, F., Cordon-Cardo, C., Lyden, D., Rafii, S., Haimovitz-Friedman, A., et al. (2003). Tumor response to radiotherapy regulated by endothelial cell apoptosis. Science 300, 1155-1159. doi: $10.1126 /$ science. 1082504

Ghosh, P., Han, G., De, M., Kim, C. K., and Rotello, V. M. (2008). Gold nanoparticles in delivery applications. Adv. Drug Deliv. Rev. 60, 1307-1315. doi: 10.1016/j.addr.2008.03.016

Gilam, A., Conde, J., Weissglas-Volkov, D., Oliva, N., Friedman, E., Artzi, N., et al. (2016). Local microRNA delivery targets Palladin and prevents metastatic breast cancer. Nat. Commun. 7:12868. doi: 10.1038/ncomms12868

Gonçalves, G., Vila, M., Portolés, M. T., Vallet-Regi, M., Gracio, J., and Marques, P. A. (2013). Nano-graphene oxide: a potential multifunctional platform for cancer therapy. Adv. Healthc. Mater. 2, 1072-1090. doi: 10.1002/adhm.201300023

Gurunathan, S., Han, J. W., Park, J. H., Kim, E., Choi, Y.-J., Kwon, D.-N., et al. (2015). Reduced graphene oxide-silver nanoparticle nanocomposite: a potential anticancer nanotherapy. Int. J. Nanomed. 10, 6257-6276. doi: 10.2147/IJN. S92449

Hadinoto, K., Sundaresan, A., and Cheow, W. S. (2013). Lipid-polymer hybrid nanoparticles as a new generation therapeutic delivery platform: a review. Eur. J. Pharm. Biopharm. 85, 427-443. doi: 10.1016/j.ejpb.2013.07.002

Halley, P. D., Lucas, C. R., McWilliams, E. M., Webber, M. J., Patton, R. A., Kural, C., et al. (2016). Daunorubicin-loaded DNA origami nanostructures circumvent drug-resistance mechanisms in a leukemia model. Small 12, 308-320. doi: 10.1002/smll.201502118

Hamburger, A. W., and Salmon, S. E. (1977). Primary bioassay of human tumor stem cells. Science 197, 461-463. doi: 10.1126/science.560061 
Han, H. D., Byeon, Y., Jeon, H. N., and Shin, B. C. (2014). Enhanced localization of anticancer drug in tumor tissue using polyethylenimine-conjugated cationic liposomes. Nanoscale Res. Lett. 9, 1-6. doi: 10.1186/1556-276X-9-209

Helbok, A., Rangger, C., Von Guggenberg, E., Saba-Lepek, M., Radolf, T., Thurner, G., et al. (2012). Research article: targeting properties of peptide-modified radiolabeled liposomal nanoparticles. Nanomed. Nanotechnol. Biol. Med. 8, 112-118. doi: 10.1016/j.nano.2011.04.012

Hemmati, H. D., Nakano, I., Lazareff, J. A., Masterman-Smith, M., Geschwind, D. H., Bronner-Fraser, M., et al. (2003). Cancerous stem cells can arise from pediatric brain tumors. Proc. Natl. Acad. Sci. U.S.A. 100, 15178-15183. doi: 10.1073/pnas.2036535100

Hermann, P. C., Huber, S. L., Herrler, T., Aicher, A., Ellwart, J. W., Guba, M., et al. (2007). Distinct populations of cancer stem cells determine tumor growth and metastatic activity in human pancreatic cancer. Cell Stem Cell 1, 313-323. doi: 10.1016/j.stem.2007.06.002

Hu, C., Niestroj, M., Yuan, D., Chang, S., and Chen, J. (2015). Treating cancer stem cells and cancer metastasis using glucose-coated gold nanoparticles. Int. J. Nanomed. 10, 2065-2077. doi: 10.2147/IJN.S72144

Huang, X., El-Sayed, I. H., Qian, W., and El-Sayed, M. A. (2006). Cancer cell imaging and photothermal therapy in the near-infrared region by using gold nanorods. J. Am. Chem. Soc. 128, 2115-2120. doi: 10.1021/ja057254a

Huang, X., and El-Sayed, M. A. (2010). Review article: gold nanoparticles: optical properties and implementations in cancer diagnosis and photothermal therapy. J. Adv. Res. 1, 13-28. doi: 10.1016/j.jare.2010.02.002

Iodice, C., Cervadoro, A., Palange, A., Key, J., Aryal, S., Ramirez, M. R., et al. (2016). Enhancing photothermal cancer therapy by clustering gold nanoparticles into spherical polymeric nanoconstructs. Opt. Lasers Eng. 76, 74-81. doi: 10.1016/j.optlaseng.2015.04.017

Jana, N. R., Gearheart, L., and Murphy, C. J. (2001). Wet chemical synthesis of high aspect ratio cylindrical gold nanorods. J. Phys. Chem. B 105, 4065-4067. doi: $10.1021 /$ jp0107964

Jiang, Q., Shi, Y., Zhang, Q., Li, N., Zhan, P., Song, L., et al. (2015). A selfassembled dna origami-gold nanorod complex for cancer theranostics. Small 11, 5134-5141. doi: 10.1002/smll.201501266

Jiang, Q., Song, C., Nangreave, J., Liu, X., Lin, L., Qiu, D. L., et al. (2012). DNA origami as a carrier for circumvention of drug resistance. J. Am. Chem. Soc. 134, 13396-13403. doi: 10.1021/ja304263n

Jung, H. S., Kong, W. H., Sung, D. K., Lee, M.-Y., Beack, S. E., Keum, D. H., et al. (2014). Nanographene oxide-hyaluronic acid conjugate for photothermal ablation therapy of skin cancer. ACS Nano 8, 260-268. doi: 10.1021/nn40 5383a

Ke, X. Y., Lin Ng, V. W., Gao, S. J., Tong, Y. W., Hedrick, J. L., and Yang, Y. Y. (2014). Co-delivery of thioridazine and doxorubicin using polymeric micelles for targeting both cancer cells and cancer stem cells. Biomaterials 35 , 1096-1108. doi: 10.1016/j.biomaterials.2013.10.049

Kim, K. R., Bang, D., and Ahn, D. R. (2016). Nano-formulation of a photosensitizer using a DNA tetrahedron and its potential for in vivo photodynamic therapy. Biomater. Sci. 4, 605-609. doi: 10.1039/C5BM00467E

Kong, B., Zhu, A., Ding, C., Zhao, X., Li, B., and Tian, Y. (2012). Carbon dotbased inorganic-organic nanosystem for two-photon imaging and biosensing of $\mathrm{pH}$ variation in living cells and tissues. Adv. Mater. 24, 5844-5848. doi: 10.1002/adma.201202599

Kong, F., Zhang, H., Qu, X., Zhang, X., Chen, D., Ding, R., et al. (2016). Gold nanorods, DNA origami, and porous silicon nanoparticle-functionalized biocompatible double emulsion for versatile targeted therapeutics and antibody combination therapy. Adv. Mater. 28, 10195-10203. doi: 10.1002/adma.201602763

Kouri, F. M., Hurley, L. A., Daniel, W. L., Day, E. S., Hua, Y., Hao, L., et al. (2015). miR-182 integrates apoptosis, growth, and differentiation programs in glioblastoma. Genes Dev. 29, 732-745. doi: 10.1101/gad.257394.114

Kumar, A., Ma, H., Zhang, X., Huang, K., Jin, S., Liu, J., et al. (2012). Gold nanoparticles functionalized with therapeutic and targeted peptides for cancer treatment. Biomaterials 33, 1180-1189. doi: 10.1016/j.biomaterials.2011.10.058

Kumar, V., Mondal, G., Slavik, P., Rachagani, S., Batra, S. K., and Mahato, R. I. (2015). Codelivery of small molecule hedgehog inhibitor and miRNA for treating pancreatic cancer. Mol. Pharm. 12, 1289-1298. doi: $10.1021 / \mathrm{mp} 500847 \mathrm{~s}$
Lang, S. H., Frame, F. M., and Collins, A. T. (2009). Prostate cancer stem cells. J. Pathol. 217, 299-306. doi: 10.1002/path.2478

Lanier, L. A., and Bermudez, H. (2015). DNA nanostructures: a shift from assembly to applications. Curr. Opin. Chem. Eng. 7, 93-100. doi: 10.1016/j.coche.2015.01.001

Lee, J. H., Yigit, M. V., Mazumdar, D., and Lu, Y. (2010). Molecular diagnostic and drug delivery agents based on aptamer-nanomaterial conjugates. Adv. Drug Deliv. Rev. 62, 592-605. doi: 10.1016/j.addr.2010.03.003

Lee, K., Drachev, V. P., and Irudayaraj, J. (2011). DNA-gold nanoparticle reversible networks grown on cell surface marker sites: application in diagnostics. ACS Nano 5, 2109-2117. doi: 10.1021/nn1030862

Li, C., Heidt, D. G., Dalerba, P., Burant, C. F., Zhang, L., Adsay, V., et al. (2007). Identification of pancreatic cancer stem cells. Cancer Res. 67, 1030-1037. doi: 10.1158/0008-5472.CAN-06-2030

Li, K., Qin, W., Li, F., Zhao, X., Jiang, B., Wang, K., et al. (2013). Nanoplasmonic imaging of latent fingerprints and identification of cocaine. Angew. Chem. Int. Edit. 52, 11542-11545. doi: 10.1002/anie.201305980

Li, K., Wang, K., Qin, W., Deng, S., Li, D., Shi, J., et al. (2015). DNA-directed assembly of gold nanohalo for quantitative plasmonic imaging of single-particle catalysis. J. Am. Chem. Soc. 137, 4292-4295. doi: 10.1021/jacs.5b00324

Li, Q., Liu, L., Liu, J.-W., Jiang, J.-H., Yu, R.-Q., and Chu, X. (2014). Nanomaterialbased fluorescent probes for live-cell imaging. TrAC Trends Anal. Chem. 58, 130-144. doi: 10.1016/j.trac.2014.03.007

Liu, K. K., Wang, C. C., Cheng, C. L., and Chao, J. I. (2009). Endocytic carboxylated nanodiamond for the labeling and tracking of cell division and differentiation in cancer and stem cells. Biomaterials 30, 4249-4259. doi: 10.1016/j.biomaterials.2009.04.056

Liu, Y., Yang, M., Zhang, J., Zhi, X., Li. C., Zhang, C., et al. (2014). Liposome encapsulated Disulfiram inhibits $\mathrm{NF} \kappa \mathrm{B}$ pathway and targets breast cancer stem cells in vitro and in vivo. Oncotarget 5, 7471-7485. doi: 10.18632 /oncotarget.2166

Liu, Y., Yang, M., Zhang, C., Pan, F., Wang, K., Yang, Y., et al. (2016). Human induced pluripotent stem cells for tumor targeted delivery of gold nanorods and enhanced photothermal therapy. ACS Nano 10, 2375-2385. doi: 10.1021/acsnano.5b07172

Lokerse, W. J., Kneepkens, E. C., Ten Hagen, T. L., Eggermont, A. M., Grüll, H., and Koning, G. A. (2016). In depth study on thermosensitive liposomes: optimizing formulations for tumor specific therapy and in vitro to in vivo relations. Biomaterials 82, 138-150. doi: 10.1016/j.biomaterials.2015.12.023

Loo, C., Lowery, A., Halas, N., West, J., and Drezek, R. (2005). Immunotargeted nanoshells for integrated cancer imaging and therapy. Nano Lett. 5, 709-711. doi: $10.1021 / \mathrm{nl} 050127 \mathrm{~s}$

Lu, W., Arumugam, S. R., Senapati, D., Singh, A. K., Arbneshi, T., Khan, S. A., et al. (2010). Multifunctional oval-shaped gold-nanoparticle-based selective detection of breast cancer cells using simple colorimetric and highly sensitive two-photon scattering assay. ACS Nano 4, 1739-1749. doi: 10.1021/nn901742q

Luo, W., Zhu, C., Su, S., Li, D., He, Y., Huang, Q., et al. (2010). Self-catalyzed, selflimiting growth of glucose oxidase-mimicking gold nanoparticles. ACS Nano 4 , 7451-7458. doi: 10.1021/nn102592h

Maitland, N. J., and Collins, A. T. (2008). Prostate cancer stem cells: a new target for therapy. J. Clin. Oncol. 26, 2862-2870. doi: 10.1200/JCO.2007.15.1472

Malmsten, M. (2013). Inorganic nanomaterials as delivery systems for proteins, peptides, DNA, and siRNA. Curr. Opin. Colloid Interface Sci. 18, 468-480. doi: 10.1016/j.cocis.2013.06.002

Manchikanti, P., and Bandopadhyay, T. K. (2010). Nanomaterials and effects on biological systems: development of effective regulatory norms. Nanoethics 4 , 77-83. doi: 10.1007/s11569-010-0084-9

Mandal, B., Bhattacharjee, H., Mittal, N., Sah, H., Balabathula, P., Thoma, L. A., et al. (2013). Core-shell-type lipid-polymer hybrid nanoparticles as a drug delivery platform. Nanomedicine 9, 474-491. doi: 10.1016/j.nano.2012.11.010

Murphy, C. J., Sau, T. K., Gole, A. M., Orendorff, C. J., Gao, J., Gou, L., et al. (2005). Anisotropic metal nanoparticles: synthesis, assembly, and optical applications. J. Phys. Chem. B 109, 13857-13870. doi: 10.1021/jp0516846

Ni, M. Z., Xiong, M., Zhang, X., Cai, G., Chen, H., Zeng, Q., et al. (2015). Poly(lactic-co-glycolic acid) nanoparticles conjugated with CD133 aptamers for targeted salinomycin delivery to $\mathrm{CD} 133^{+}$osteosarcoma cancer stem cells. Int. J. Nanomed. 10, 2537-2554. doi: 10.2147/IJN.S78498 
Nikoobakht, B., and El-Sayed, M. A. (2003). Preparation and growth mechanism of gold Nanorods (NRs) using seed-mediated growth method. Chem. Mater. 15, 1957-1962. doi: 10.1021/cm0207321

Novoselov, K. S., Geim, A. K., Morozov, S. V., Jiang, D., Zhang, Y., Dubonos, S. V., et al. (2004). Electric field effect in atomically thin carbon films. Science 306, 666. doi: 10.1126/science. 1102896

O’Brien, C. A., Pollett, A., Gallinger, S., and Dick, J. E. (2007). A human colon cancer cell capable of initiating tumour growth in immunodeficient mice. Nature 445, 106-110. doi: 10.1038/nature05372

Oli, M. (2010). Aptamer conjugated gold nanorods for targeted nanothermal radiation of Glioblastoma cancer cells (A novel selective targeted approach to cancer treatment). Young Sci. J. 3, 18-25. doi: 10.4103/0974-6102.68740

Orza, A., Olenic, L., Pruneanu, S., Pogacean, F., and Biris, A. S. (2010). Morphological and electrical characteristics of amino acid-AuNP nanostructured two-dimensional ensembles. Chem. Phys. 373, 295-299. doi: 10.1016/j.chemphys.2010.06.001

Orza, A., Soriţău, O., Tomuleasa, C., Olenic, L., Florea, A., Pana, O., et al. (2013). Reversing chemoresistance of malignant glioma stem cells using gold nanoparticles. Int. J. Nanomed. 8, 689-702. doi: 10.2147/IJN.S37481

Ouyang, X., Li, J., Liu, H., Zhao, B., Yan, J., Ma, Y., et al. (2013). Rolling circle amplification-based DNA origami nanostructrures for intracellular delivery of immunostimulatory drugs. Small 9, 3082-3087. doi: 10.1002/smll.201300458

Panyam, J., and Labhasetwar, V. (2003). Biodegradable nanoparticles for drug and gene delivery to cells and tissue. Adv. Drug Deliv. Rev. 55, 329-347. doi: 10.1016/S0169-409X(02)00228-4

Patra, C. R., Bhattacharya, R., Mukhopadhyay, D., and Mukherjee, P. (2010). Fabrication of gold nanoparticles for targeted therapy in pancreatic cancer. $A d v$. Drug Deliv. Rev. 62, 346-361. doi: 10.1016/j.addr.2009.11.007

Peng, C. A., and Wang, C. H. (2011). "CD133-positive cancer stem-like cells ablated by gold nanorod-mediated near-infrared laser treatment," in Nanoelectronics Conference (INEC), 2011 IEEE 4th International (Tao-Yuan), $1-2$.

Peng, T., Qin, W., Wang, K., Shi, J., Fan, C., and Li, D. (2015). Nanoplasmonic imaging of latent fingerprints with explosive RDX residues. Anal. Chem. 87, 9403-9407. doi: 10.1021/acs.analchem.5b02248

Qin, W. W., Wang, S. P., Li, J., Peng, T. H., Xu, Y., Wang, K., et al. (2015). Visualizing dopamine released from living cells using a nanoplasmonic probe. Nanoscale 7, 15070-15074. doi: 10.1039/C5NR04433B

Reya, T., Morrison, S. J., Clarke, M. F., and Weissman, I. L. (2001). Stem cells, cancer, and cancer stem cells. Nature 414, 105-111. doi: 10.1038/35102167

Ricci-Vitiani, L., Lombardi, D. G., Pilozzi, E., Biffoni, M., Todaro, M., Peschle, C., et al. (2007). Identification and expansion of human colon-cancer-initiating cells. Nature 445, 111-115. doi: 10.1038/nature05384

Setua, S., Ouberai, M., Welland, M., Piccirillo, S. G., and Watts, C. (2014). Cisplatin-tethered gold nanospheres for multimodal chemo-radiotherapy of glioblastoma. Nanoscale 6, 10865-10873. doi: 10.1039/C4NR03693J

Shao, W., Paul, A., Zhao, B., Lee, C., Rodes, L., and Prakash, S. (2013). Carbon nanotube lipid drug approach for targeted delivery of a chemotherapy drug in a human breast cancer xenograft animal model. Biomaterials 34, 10109-10119. doi: 10.1016/j.biomaterials.2013.09.007

Shen, K. Y., Liu, H. Y., Li, H. J., Wu, C. C., Liou, G. G., Chang, Y. C., et al. (2016). A novel liposomal recombinant lipoimmunogen enhances anti-tumor immunity. J. Control. Release 233, 57-63. doi: 10.1016/j.jconrel.2016.05.008

Shen, Y. A., Li, W. H., Chen, P. H., He, C. L., Chang, Y. H., and Chuang, C. M. (2015). Intraperitoneal delivery of a novel liposome-encapsulated paclitaxel redirects metabolic reprogramming and effectively inhibits cancer stem cells in Taxol ${ }^{\circledR}$-resistant ovarian cancer. Am. J. Transl. Res. 7, 841-855. Available online at: www.ajtr.org

Singh, S. K., Clarke, I. D., Terasaki, M., Bonn, V. E., Hawkins, C., Squire, J., et al. (2003). Identification of a cancer stem cell in human brain tumors. Cancer Res. $63,5821-5828$

Skrabalak, S. E., Chen, J., Sun, Y., Lu, X., Au, L., Cobley, C. M., et al. (2008). Gold nanocages: synthesis, properties, and applications. Acc. Chem. Res. 41, 1587-1595. doi: 10.1021/ar800018v

Stupp, R., and Hegi, M. E. (2007). Targeting brain-tumor stem cells. Nat. Biotechnol. 25, 193-194. doi: 10.1038/nbt0207-193

Sun, T., Wang, Y. C., Wang, F., Du, J. Z., Mao, C. Q., Sun, C. Y., et al. (2014a). Cancer stem cell therapy using doxorubicin conjugated to gold nanoparticles via hydrazone bonds. Biomaterials 35, 836-845 doi: 10.1016/j.biomaterials.2013.10.011

Sun, T., Wang, Y., Wang, Y. C., Xu, J. B., Zhao, X., Vangveravong, S., et al. (2014b). Using SV119-gold nanocage conjugates to eradicate cancer stem cells through a combination of photothermal and chemo therapies. Adv. Healthc. Mater. 3, 1283-1291. doi: 10.1002/adhm.201400026

Sun, Y., and Xia, Y. (2002). Shape-controlled synthesis of gold and silver nanoparticles. Science 298, 2176-2179. doi: 10.1126/science.1077229

Swaminathan, S. K., Roger, E., Toti, U., Niu, L., Ohlfest, J. R., and Panyam, J. (2013). CD133-targeted paclitaxel delivery inhibits local tumor recurrence in a mouse model of breast cancer. J. Control. Release 171, 280-287. doi: 10.1016/j.jconrel.2013.07.014

Thompson, D. T. (2007). Using gold nanoparticles for catalysis. Nanotoday 2 , 40-43. doi: 10.1016/S1748-0132(07)70116-0

Tian, B., Wang, C., Zhang, S., Feng, L., and Liu, Z. (2011). Photothermally enhanced photodynamic therapy delivered by nano-graphene oxide. ACS Nano 5, 7000-7009. doi: $10.1021 / \mathrm{nn} 201560 \mathrm{~b}$

Tian, F., Conde, J., Bao, C., Chen, Y., Curtin, J., and Cui, D. (2016). Gold nanostars for efficient in vitro and in vivo real-time SERS detection and drug delivery via plasmonic-tunable Raman/FTIR imaging. Biomaterials 106, 87-97. doi: 10.1016/j.biomaterials.2016.08.014

Tiloke, C., Phulukdaree, A., Anand, K., Gengan, R. M., and Chuturgoon, A. A. (2016). Moringa oleifera gold nanoparticles modulate oncogenes, tumor suppressor genes, and caspase-9 splice variants in A549 Cells. J. Cell. Biochem. 117, 2302-2314. doi: 10.1002/jcb.25528

Tomuleasa, C., Soritau, O., Orza, A., Dudea, M., Petrushev, B., Mosteanu, O., et al. (2012). Gold nanoparticles conjugated with cisplatin/doxorubicin/ capecitabine lower the chemoresistance of hepatocellular carcinoma-derived cancer cells. J. Gastrointestin. Liver Dis. 21, 187-196.

Torchilin, V. P. (2006). Micellar nanocarriers: pharmaceutical perspectives. Pharm. Res. 24, 1-16. doi: 10.1007/s11095-006-9132-0

Usacheva, M., Swaminathan, S. K., Kirtane, A. R., and Panyam, J. (2014). Enhanced photodynamic therapy and effective elimination of cancer stem cells using surfactant-polymer nanoparticles. Mol. Pharm. 11, 3186-3195. doi: $10.1021 / \mathrm{mp} 5003619$

Wagstaff, A. J., Brown, S. D., Holden, M. R., Craig, G. E., Plumb, J. A., Brown, R. E. et al. (2012). Cisplatin drug delivery using gold-coated iron oxide nanoparticles for enhanced tumour targeting with external magnetic fields. Inorg. Chim. Acta 393, 328-333. doi: 10.1016/j.ica.2012.05.012

Wang, J., Sefah, K., Altman, M. B., Chen, T., You, M., Zhao, Z., et al. (2013). Aptamer-conjugated nanorods for targeted photothermal therapy of prostate cancer stem cells. Chem. Asian J. 8, 2417-2422. doi: 10.1002/asia.201300375

Wang, L., Liu, Y., Li, W., Jiang, X. M., Ji, Y. L., Wu, X. C., et al. (2011). Selective Targeting of gold nanorods at the mitochondria of cancer cells: implications for cancer therapy. Nano Lett. 11, 772-780. doi: 10.1021/nl103992v

Wang, X., Low, X. C., Hou, W., Abdullah, L. N., Toh, T. B., Rashid, M. M. A., et al. (2014). Epirubicin-adsorbed nanodiamonds kill chemoresistant hepatic cancer stem cells. ACS Nano 8, 12151-12166. doi: 10.1021/nn503491e

Wang, Z., Zhang, J., Ekman, J. M., Kenis, P. J., and Lu, Y. (2010). DNA-Mediated control of metal nanoparticle shape: one-pot synthesis and cellular uptake of highly stable and functional gold nanoflowers. Nano Lett. 10, 1886-1891. doi: $10.1021 / \mathrm{nl} 100675 \mathrm{p}$

Wei, X., Senanayake, T. H., Warren, G., and Vinogradov, S. V. (2013). Hyaluronic acid-based nanogel-drug conjugates with enhanced anticancer activity designed for the targeting of cd44-positive and drug-resistant tumors. Bioconjugate Chem. 24, 658-668. doi: 10.1021/bc300632w

Whitesides, G. M., Mathias, J. P., and Seto, C. T. (1991). Molecular self-assembly and nanochemistry: a chemical strategy for the synthesis of nanostructures. Science 254, 1312. doi: 10.1126/science. 1962191

Wu, H., Shi, H., Zhang, H., Wang, X., Yang, Y., Yu, C., et al. (2014). Prostate stem cell antigen antibody-conjugated multiwalled carbon nanotubes for targeted ultrasound imaging and drug delivery. Biomaterials 35, 5369-5380. doi: 10.1016/j.biomaterials.2014.03.038

Xia, Y., Li, W., Cobley, C. M., Chen, J., Xia, X., Zhang, Q., et al. (2011). Gold nanocages: from synthesis to theranostic applications. Acc. Chem. Res. 44, 914-924. doi: 10.1021/ar200061q

Xia, Y., Xiong, Y., Lim, B., and Skrabalak, S. E. (2009). Shape-controlled synthesis of metal nanocrystals: simple chemistry meets complex 
physics? Angew. Chem. Int. Edit. 48, 60-103. doi: 10.1002/anie.2008 02248

Xia, Z., Wang, P., Liu, X., Liu, T., Yan, Y., Yan, J., Zhong, J., Sun, G., He, D., et al. (2016). Tumor-penetrating peptide-modified DNA tetrahedron for targeting drug delivery. Biochemistry 55, 1326-1331. doi: 10.1021/acs.biochem.5b01181

Xie, J., Zhang, Q., Lee, J. Y., and Wang, D. I. (2008). The synthesis of SERSactive gold nanoflower tags for in vivo applications. ACS Nano 2, 2473-2480. doi: $10.1021 / \mathrm{nn} 800442 \mathrm{q}$

Xu, C. F., Liu, Y., Shen, S., Zhu, Y. H., and Wang, J. (2015). Targeting glucose uptake with siRNA-based nanomedicine for cancer therapy. Biomaterials 51, 1-11. doi: 10.1016/j.biomaterials.2015.01.068

Xu, Y., Li, K., Qin, W., Zhu, B., Zhou, Z., Shi, J., et al. (2015). Unraveling the role of hydrogen peroxide in $\alpha$-synuclein aggregation using an ultrasensitive nanoplasmonic probe. Anal. Chem. 87, 1968-1973. doi: 10.1021/ac5043895

Xu, Y., Chenna, V., Hu, C., Sun, H. X., Khan, M., Bai, H., et al. (2012). Polymeric nanoparticle-encapsulated hedgehog pathway inhibitor HPI-1 (NanoHHI) inhibits systemic metastases in an orthotopic model of human hepatocellular carcinoma. Clin. Cancer Res. 18, 1291-1302. doi: 10.1158/1078-0432.CCR-11-0950

Xu, Y., Wang, J., Li, X., Liu, Y., Dai, L., Wu, X., et al. (2014). Selective inhibition of breast cancer stem cells by gold nanorods mediated plasmonic hyperthermia. Biomaterials 35, 4667-4677. doi: 10.1016/j.biomaterials.2014.02.035

Yao, H. J., Zhang, Y. G., Sun, L., and Liu, Y. (2014). The effect of hyaluronic acid functionalized carbon nanotubes loaded with salinomycin on gastric cancer stem cells. Biomaterials 35, 9208-9223. doi: 10.1016/j.biomaterials.2014.07.033

Yi, Y., Kim, H. J., Mi, P., Zheng, M., Takemoto, H., Toh, K., et al. (2016). Targeted systemic delivery of siRNA to cervical cancer model using cyclic RGD-installed unimer polyion complex-assembled gold nanoparticles. J. Control Release 244, 247-256. doi: 10.1016/j.jconrel.2016.08.041

You, J., Zhao, J., Wen, X., Wu, C., Huang, Q., Guan, F., et al. (2015). Chemoradiation therapy using cyclopamine-loaded liquid-lipid nanoparticles and lutetium-177-labeled core-crosslinked polymeric micelles. J. Control. Release 202, 40-48. doi: 10.1016/j.jconrel.2015.01.031

Yuan, Y., Zhao, Y., Wu, N., Wen, J., Chen, L., Wei, Y., et al. (2013). A novel pegylated liposome-encapsulated SANT75 suppresses tumor growth through inhibiting hedgehog signaling pathway. PLoS ONE 8:e60266. doi: 10.1371/journal.pone.0060266
Zhang, Q., Jiang, Q., Li, N., Dai, L., Liu, Q., Song, L., et al. (2014). DNA origami as an in vivo drug delivery vehicle for cancer therapy. ACS Nano 8, 6633-6643. doi: $10.1021 / \mathrm{nn} 502058 \mathrm{j}$

Zhang, Y., Cui, Z., Kong, H., Xia, K., Pan, L., Li, J., et al. (2016). One-shot immunomodulatory nanodiamond agents for cancer immunotherapy. $A d v$. Mater. 28, 2699-2708. doi: 10.1002/adma.201506232

Zhao, L., Xu, Y. H., Akasaka, T., Abe, S., Komatsu, N., Watari, F., et al. (2014). Polyglycerol-coated nanodiamond as a macrophage-evading platform for selective drug delivery in cancer cells. Biomaterials 35, 5393-5406. doi: 10.1016/j.biomaterials.2014.03.041

Zhao, Y. X., Shaw, A., Zeng, X., Benson, E., Nyström, A. M., and Högberg, B. (2012). DNA origami delivery system for cancer therapy with tunable release properties. ACS Nano 6, 8684-8691. doi: 10.1021/nn3022662

Zheng, X., Liu, Q., Jing, C., Li, Y., Li, D., Luo, W., et al. (2011). Catalytic gold nanoparticles for nanoplasmonic detection of DNA hybridization. Angew. Chem. Int. Edit. 50, 11994-11998. doi: 10.1002/anie.2011 05121

Zhu, G., Zheng, J., Song, E., Donovan, M., Zhang, K., Liu, C., et al. (2013). Self-assembled, aptamer-tethered DNA nanotrains for targeted transport of molecular drugs in cancer theranostics. Proc. Natl. Acad. Sci. U.S.A. 110, 7998-8003. doi: 10.1073/pnas.1220817110

Zhuang, X., Ma, X., Xue, X., Jiang, Q., Song, L., Dai, L., et al. (2016). A photosensitizer-loaded DNA origami nanosystem for photodynamic therapy. ACS Nano 10, 3486-3495. doi: 10.1021/acsnano. 5 b07671

Conflict of Interest Statement: The authors declare that the research was conducted in the absence of any commercial or financial relationships that could be construed as a potential conflict of interest.

Copyright (c) 2017 Qin, Huang, Chen and Zhang. This is an open-access article distributed under the terms of the Creative Commons Attribution License (CC BY). The use, distribution or reproduction in other forums is permitted, provided the original author(s) or licensor are credited and that the original publication in this journal is cited, in accordance with accepted academic practice. No use, distribution or reproduction is permitted which does not comply with these terms. 